\title{
Does litigation change managers' beliefs about the value of voluntarily disclosing bad news?
}

\author{
Mary Brooke Billings, et al. [full author details at the end of the article]
}

Accepted: 10 January 2021 / Published online: 31 May 2021

(C) This is a U.S. government work and not under copyright protection in the U.S.; foreign copyright protection may apply 2021

\begin{abstract}
Research suggests that earnings-disclosure-related litigation causes managers to reduce subsequent disclosure, perhaps stemming from a belief that even their good faith disclosures will cause them trouble. This paper considers unexplored dimensions of disclosure and alternative channels of disclosure to provide additional evidence that speaks to how litigation shapes managers' disclosure strategies. Consistent with Skinner (1994)'s classic legal liability hypothesis, we find that, while managers reduce and delay forecasts of positive earnings news following litigation, they increase the frequency and timeliness of their bad news forecasts. Moreover, many managers who were nonguiders prior to facing legal scrutiny begin guiding following litigation. Managers also maintain (if not increase) the information they provide via press releases and during conference calls following litigation. Supporting the notion that managers use disclosure to walk down expectations, additional analyses document an increase in the likelihood that lawsuit firms report earnings that beat consensus forecasts in the post-lawsuit period. Collectively, our evidence suggests that following litigation managers continue to view disclosure as a valuable tool that shapes their firms' information environments and reduces expected legal costs. In so doing, it supports an important alternative viewpoint of how firms respond to litigation as well as the effectiveness of litigation as a disciplining mechanism.
\end{abstract}

Keywords Voluntary disclosure $\cdot$ Litigation risk $\cdot$ Class action lawsuits · Earnings guidance JEL classifications $\mathrm{M} 41 \cdot \mathrm{K} 22 \cdot \mathrm{G} 14$

\footnotetext{
This paper benefited from the insightful comments of Abigail Allen, Brian Bushee, Jing Chen, Mike Drake, Peter Easton (the editor), Frank Heflin (discussant), Bob Holthausen, Justin Hopkins, Bill Kross, Melissa Lewis-Western, Bob Jennings, Jeremy Michels, Mike Mikhail, Inho Suk, Jake Thornock, Beverly Walther, Joe Weber, Jun Yang (discussant), three anonymous reviewers, and workshop participants at Brigham Young University, Baruch College, Fordham University, Indiana University, Northwestern University, University of North Carolina at Chapel Hill, College of William and Mary, the University of Pennsylvania, University of California, San Diego, University of Rochester, Indiana University's Finance Symposium on Financial Agents, Carnegie Mellon's Accounting Symposium, the AAA Conference, the UIC Accounting Research Conference, Yale SOM Fall Conference, and the University at Buffalo.
} 


\section{Introduction}

Rogers and Van Buskirk (2009) document a decline in voluntary disclosure following litigation and suggest that litigation causes managers to revise their beliefs about the costs and benefits of disclosure - seemingly adopting a belief that even disclosures made in good faith will get them into trouble. As Lowry (2009) observes, this finding should concern both shareholders and policymakers. If managers respond to litigation with reduced disclosure, the risk of future litigation stemming from a failure to preempt earnings disappointments may increase and, more generally, the firm's information environment may suffer. Consistent with these concerns, Rogers and Van Buskirk (2009) conclude that their findings call into question litigation's effectiveness as a governance mechanism and suggest that regulators or harmed shareholders may need to take action to motivate improved disclosure going forward.

In this paper, we consider unexplored dimensions of disclosure as well as alternative disclosure channels to provide additional evidence that speaks to litigation's role in shaping managers' disclosure strategies. Because large earnings disappointments trigger lawsuit filings, ${ }^{1}$ we examine whether managers respond to litigation by adjusting their disclosure strategy in a manner that increases the likelihood of reporting earnings that beat prevailing earnings expectations. In so doing, we directly test whether managers' disclosures become more asymmetrically conservative in response to litigation.

We first examine whether managers' disclosure responses differ depending on the sign of the news disclosed - that is, the extent to which the disclosure raises versus lowers expectations of upcoming earnings realizations. We then explore whether managers adjust the information they disclose via their press releases and in their conference calls. In our final set of analyses, we test for broad post-lawsuit changes in firms' overall information environments.

Litigation potentially influences managerial disclosures in opposing ways. If litigation reinforces the value of early warnings (as well as underscores the costs of ex post inaccurate positive guidance), then managers may respond by reducing their disclosure of good news forecasts but, at the same time, by increasing the frequency and timeliness of their cautionary forecasts. Consistent with this notion of asymmetric disclosure incentives, Skinner (1994) finds that managers generally warn of impending negative earnings news far more frequently than they provide positive forecasts. Subsequent work documents that this asymmetry in disclosure likelihood increases

\footnotetext{
${ }^{1}$ A typical shareholder lawsuit brought under Rule 10b-5 of the Securities Exchange Act of 1934 alleges that managers of the company made false or misleading statements and/or failed to disclose material information in a timely manner to the market, resulting in a period when the firm's stock price was artificially inflated. The revelation of negative news along with a considerable drop in the firm's stock price often triggers the filing of a shareholder lawsuit. As a result, shareholders can and do sue both guiding and nonguiding firms for the failure to disclose negative earnings news in a timely manner. That is, managers face legal scrutiny for warnings that are deemed too little or too late, but managers also face scrutiny for remaining silent in advance of negative earnings revelations.
} 
with ex ante litigation risk (Cao and Narayanamoorthy 2011; Houston et al. 2019). ${ }^{2}$ Alternatively, litigation may cause managers to revise their beliefs about the value of any disclosure. Consistent with this view, Johnson et al. (2001) and Naughton et al. (2019) document reductions in the disclosure of both good and bad news in response to reductions in litigation risk.

The above studies focus on the link between ex ante litigation risk and disclosure. In contrast, examining ex post disclosure responses to actual litigation, Rogers and Van Buskirk (2009) conclude that the experience of litigation encourages managers to reduce their overall disclosure. Yet, earnings-related lawsuits allege that managers failed to warn in a timely manner. Thus litigation may motivate managers to increase the frequency and timeliness of their cautionary disclosure, notwithstanding their choice to reduce other guidance.

To investigate how managers' disclosure strategy changes in response to litigation, we hand-collect a sample of 654 firms that faced earnings-disclosure-related lawsuits following the passage of Regulation Fair Disclosure ("Reg FD") in 2000. Consistent with the results of Rogers and Van Buskirk (2009), we find that overall forecast quantity falls in the post-lawsuit period, relative to the pre-lawsuit period, for sued firms and as compared to the changes observed for a sample of propensity-matched peers. Yet, inconsistent with the notion that managers discount the value of all disclosure post litigation, we find that the sign and timing of the forecast matter: while managers reduce and delay their forecasts of positive (and confirming) earnings news following litigation, their bad news forecasts actually increase and become timelier. ${ }^{3}$

We also investigate whether managers respond differently depending upon their experience during litigation. As Lowry (2009, p. 158) notes: "managers of sued firms are likely to directly observe the ways in which their prior disclosures are used (or at least attempted to be used) to prove wrongdoing." As a result, managers of sued firms who guided in the past may become reticent to continue providing disclosures that are inherently predictive and therefore leave them vulnerable to investor-plaintiff "Monday-morning quarterbacking." At the same time, managers of sued firms who face allegations that they failed to warn at all may believe that the absence of guidance (i.e., their silence) got their firm into trouble, and they may begin viewing disclosure as a

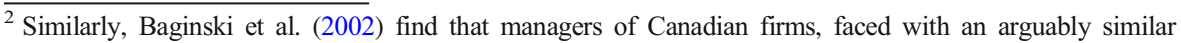
business environment but a less litigious legal environment, are more likely to disclose good news, relative to U.S. firms, but that U.S. firms issue more warnings during periods of declining earnings. Nelson and Pritchard (2007) find that managers increase their use of cautionary language following increases in litigation risk but do not remove cautionary language when litigation risk declines.

${ }^{3}$ Rogers and Van Buskirk (2009) infer from the absence of significant increases in signed management forecast error, earnings surprise, or earnings announcement abnormal returns that the reduction in disclosure they document does not stem from managers' adopting a more conservative disclosure strategy; i.e., managers do not adjust the amount of their disclosure depending upon the direction of the news. In our tests, we directly measure the sign of the news disclosed when testing for changes in disclosure.

4 The Private Securities Litigation Reform Act ("PSLRA") provides safe harbors for some forward-looking statements made by managers. Nonetheless, the extent to which a statement qualifies for immunity under the safe harbor provision depends upon whether it is accompanied by meaningful cautionary language. Thus, as Olazábal (2000) observes, the applicability of the "safe harbor" provision depends upon the disclosure context. As a result, managers remain vulnerable to "Monday-morning quarterbacking" or "fraud-by-hindsight" lawsuits in relation to their forward-looking disclosures (Olazábal 2000; Ribstein 2006; Rose 2008).
} 
way to minimize expected legal costs. Nevertheless, the bulk of the costs imposed by lawsuit filings relate to legal, time, and reputational costs borne by lawsuit managers (Kim and Skinner 2012). Consequently, managers' disclosure responses may also differ depending upon the extent to which the firm's litigation matters prompt media scrutiny and the manager faces increased reputational costs.

Shifting our attention to managers' experience during litigation, our evidence indicates that managers do not adopt the belief that a higher level of disclosure harmed their cases. We find that those managers who were guiders prior to the lawsuit (including those whose own prior warnings faced scrutiny for being insufficient during the litigation process) do not stop guiding; rather, they give cautionary guidance earlier and more frequently in the post-lawsuit period. Moreover, many managers who were nonguiders prior to facing legal scrutiny begin guiding following litigation, and, in fact, they are more likely to do so than their nonsued counterparts. Exploiting variation in media scrutiny, we find that our earlier findings indicating more frequent and timely warnings following litigation concentrate among those firms that experienced abovemedian changes in media coverage of their litigation matters. This evidence contradicts the notion that legal and media scrutiny during litigation prompts managers to begin viewing all disclosure - especially good faith, cautionary disclosures - as more costly.

The question remains, however, whether managers adjust the information they disclose via other channels. Expanding our measures of disclosure, we find no evidence of reduced overall disclosure. Instead, we find that firms' press releases that discuss negative news increase in the post-lawsuit period, while their press releases discussing positive and neutral news remain unchanged. We also find that managers do not limit the information they provide via their conference calls. After a lawsuit, managers increase the length of their introductory remarks, while sustaining their prior level of responsiveness to analyst questions during their conference calls.

Our final set of tests broadens the scope of analysis to consider changes in the overall information environment of the firm. Conditional upon the decision to provide a forecast, we find no evidence that managers' willingness or ability to provide an accurate forecast changes in the post-lawsuit period. We also detect no changes in liquidity. Combined, this evidence quiets concerns that managers respond in a way that harms overall transparency (Lowry 2009). Further, we find that positive earnings surprises and the likelihood of beating consensus forecasts both increase in the postlawsuit period. This suggests that the increased frequency and timeliness of cautionary forecasts along with accompanying disclosure in both press releases and conference calls may help walk down expectations. More generally, it contradicts the notion that firms adopt disclosure policies that leave the firm more vulnerable to litigation.

Collectively, our evidence suggests that following litigation managers continue to view disclosure as a way to shape their firms' information environments and reduce expected legal costs. Accordingly, our paper contributes to the rich literature that examines the relation between disclosure and litigation. Cao and Narayanamoorthy (2011), Houston et al. (2019), and Naughton et al. (2019) find that managers respond to increases (decreases) in expected litigation risk with increases (decreases) in disclosure, while Field et al. (2005) and Billings and Cedergren (2015) find that increased disclosure links to a reduced risk of actual litigation. Combined, this evidence supports the classic legal liability hypothesis of Skinner (1994): managers seek to and do use disclosure to lower the firms' litigation costs. Yet other evidence suggests that 
managers respond to actual litigation by adopting the belief that disclosures - even those made in good faith - may court trouble (Rogers and Van Buskirk 2009). As Lowry (2009) notes, survey and empirical evidence indicates that managers view good and bad news disclosures differently, particularly in the context of managing litigation risk (Graham et al. 2005; Skinner 1994), and thus the evidence of Rogers and Van Buskirk (2009) raises questions when compared to the literature. By directly considering the sign of the news when testing for changes in disclosure, our evidence reconciles these conflicting findings.

In so doing, our evidence supports an important alternative viewpoint of how firms respond to litigation as well as the effectiveness of litigation as a disciplining mechanism. Rogers and Van Buskirk (2009) conclude that regulatory and contractual intervention is needed, because managers do not respond with more frequent and timely bad news disclosures. ${ }^{5}$ Expanding analyses to consider unexplored dimensions of disclosure, our paper concludes just the opposite. Most notably, our evidence suggests that managers adopt a more conservative disclosure strategy by increasing their efforts to walk down prevailing expectations to preempt negative surprises while maintaining disclosure via other channels. This paints a different picture of managers' responses to litigation and accordingly contradicts the notion that regulators and shareholders should be troubled and take action.

Our paper also has implications for academic research. A well-cited review of the disclosure literature notes that existing evidence suggests that litigation decreases managers' incentives to disclose (Beyer et al. 2010). Consistent with this view, many theoretical and empirical papers assume a reduced level of disclosure following actual litigation to inform their predictions (e.g., Files et al. 2009; Brochet et al. 2011; Laux and Stocken 2012). Yet recent work by Marinovic and Varas (2016) theorizes that litigation concerns crowd out positive disclosures while increasing the frequency of negative disclosures. Nonetheless, the empirical evidence remains mixed. ${ }^{6}$ Because our findings provide a more refined view of how disclosure changes in response to actual litigation, our paper helps inform a growing stream of theoretical and empirical research in making predictions about how disclosure behavior varies with litigation risk in the broader population of firms. Further, researchers often focus on documenting changes in the frequency, likelihood, and precision of disclosure. Consistent with the work of Heflin et al. (2012), Heflin et al. (2016), our findings call attention to the importance of considering the sign of disclosure when examining changes in disclosure behavior, particularly in contexts where managers may face asymmetric disclosure incentives.

\footnotetext{
${ }_{5}^{5}$ Specifically, Rogers and Van Buskirk (2009, p. 137) conclude that, "if regulators are interested in timely and informative disclosures, they may be troubled that the current environment results in exactly the opposite for firms involved in litigation" and that "if litigants desire improved disclosure going forward, they may need to explicitly include such changes in settlement agreements, rather than hope the target firms improve their disclosure voluntarily."

${ }^{6}$ For example, Houston et al. (2019) find that managers make fewer bad news forecasts when they expect litigation risk to be lower (as identified by a key ruling by the Ninth Circuit), but they detect no change in good news forecasts. However, Naughton et al. (2019) document reductions in the disclosure of both good and bad news in response to expected reductions in litigation risk (as identified by a different court ruling, i.e., the Morrison ruling).
} 


\section{Data and descriptive statistics}

\subsection{Litigation sample}

The classic litigation risk hypothesis advanced by Skinner (1994) focuses on managers' incentives to preempt negative earnings surprises. Accordingly, we assemble a sample of firms that faced litigation from 2001 through 2015. As shown in Panel A of Table 1, we begin by obtaining a list of 3,151 lawsuits from the litigation database maintained by Stanford Law School's Securities Class Action Clearinghouse ("SCAC") (http:// securities.stanford.edu). The SCAC covers all securities class action lawsuits filed in Federal Court. Because our predictions relate to disclosure in the context of earnings news, we narrow this list to earnings-disclosure-related lawsuits brought under Rule 10b-5 of the Securities Exchange Act of 1934. A typical 10b-5 lawsuit alleges that the company made false or misleading statements and/or failed to disclose material adverse information in a timely manner to the market, resulting in a period when the firm's stock price was artificially inflated. The class of investors (known as the "plaintiff class") who purchased the company's stock during this time (known as the "class period") claims damages that result from managers' inadequate disclosure. The revelation of negative earnings news (along with a drop in the firm's stock price) typically triggers the filing of the lawsuit.

Because Skinner's (1994) theory does not suggest that managers seek to use disclosure in advance of fraud or financial misreporting revelations to limit legal liability, we review each complaint to identify cases where managers are alleged to have failed to disclose earnings news in a timely manner. ${ }^{8}$ To confirm the nature of each claim, we read the first identified complaint for the lawsuit. Consistent with work examining disclosure-related litigation, we then remove 2,219 lawsuits that do not relate to firms' earnings disclosures. ${ }^{9}$ We also remove 278 lawsuits for which sufficient data is not available to conduct our multivariate tests. As shown in Panel A of Table 1, this process identifies 630 unique firms that faced 654 lawsuits based on the firms' earnings disclosures during our sample period. Figure 1 shows how the sample distribution varies across time. The number of earnings-disclosure-related lawsuits peaked around 2003 and 2004, with 71 and 64 lawsuits, respectively, after the dot-com bubble burst.

Reading the lawsuit complaints along with other public documents (e.g., subsequent legal filings, SEC filings, press releases, and media coverage) allows us to identify lawsuit durations, outcomes, allegations, and prior disclosure behavior. Although we find that slightly over half of all lawsuits are dismissed $(344 \div 654=53 \%)$, Panel B of Table 1 indicates that resolution does not happen quickly in most cases. The average

\footnotetext{
${ }^{7}$ We end our sample period in 2015 , as we require eight quarters of data after the quarter in which the firm was sued.

${ }^{8}$ Of course, managers may use guidance (in combination with financial reporting decisions) to delay fraud revelations. Nonetheless, managers are unlikely to view guidance as a means to prevent lawsuits that allege fraud, but they are likely to view guidance as a means to guard against claims that they failed to promptly disclose negative earnings news. This allows our paper to fit within the longstanding stream of disclosure research that examines the link between guidance and litigation risk (Skinner 1994, 1997; Field et al. 2005). ${ }^{9}$ Specifically, we remove lawsuits that focus on, among other things, financial statement fraud and accounting irregularities; the behavior of underwriters, analysts, investment banks, brokerage firms, and mutual funds; and filings that relate to Chinese reverse mergers, merger and acquisition activity, initial public offerings, seasoned equity offerings, and the credit crisis.
} 
Table 1 Lawsuit Data

Panel A: Sample selection

Total lawsuits (2001 through 2015)

Remove non-earnings disclosure-related lawsuits

Remove lawsuits of firms with missing data

Lawsuit sample

Unique firms sued

Panel B: Lawsuit outcomes and characteristics

Class length (days)

Class period return

Days to resolution (all lawsuits)

Days to resolution (dismissed)*

Days to resolution (settled)*

Settlement (\$ million)

Panel C: Legal scrutiny and prior disclosure behavior

Did the firm give any guidance in the 8 quarters prior to the lawsuit?

Did the lawsuit complaint allege the absence of a prior warning?

Did the lawsuit complaint explicitly cite insufficient prior warnings?

\section{Number of lawsuits}

3,151

654

630

$\begin{array}{cccl}\text { N } & \text { Mean } & \text { Median } & \text { St. Dev. } \\ 654 & 341 & 258 & 303 \\ 654 & -20.3 \% & -22.3 \% & 47.1 \% \\ 654 & 1012 & 880 & 666 \\ 344 & 683 & 616 & 484 \\ 301 & 1387 & 1232 & 648 \\ 301 & 68.1 & 9.5 & 450.7\end{array}$

Table 1 describes sample selection procedures and lawsuit characteristics. Panel A describes lawsuit collection procedures. Panel B provides descriptive statistics on the length of the lawsuit's class action period, the time until settlement, dismissal, or other resolution and the amount of settlement (if any). Panel $\mathrm{C}$ describes the allegations contained in the lawsuit complaints regarding the firms' prior disclosure behavior.

* Note: Nine lawsuits were pending at the time this study was performed $(301+344+9=654)$

dismissed lawsuit takes almost two years to resolve. For nondismissed lawsuits, the average time to resolution approaches nearly four years. Further, consistent with Kim and Skinner (2012), we find that the vast majority of settlements are not large: the median settlement amount for the 301 settled lawsuits in our sample is $\$ 9.5$ million. As Kim and Skinner (2012) note, the main penalties borne by lawsuit managers relate to legal, reputational, and time costs.

Shareholders can and do use managers' guidance behavior (both the presence of positive news forecasts and the lack of cautionary warnings) as evidence of wrongdoing (Sale 2002; Johnson et al. 2007). Consistent with this notion, as shown in Panel C, we find that $483(74 \%)$ of the firms in our sample have a history of guidance (GUIDER) in the eight quarters prior to the lawsuit filing. With regard to plaintiff allegations, $280(43 \%)$ lawsuits include allegations that managers failed to provide a cautionary warning. The other 374 lawsuits are those in which managers did provide a 


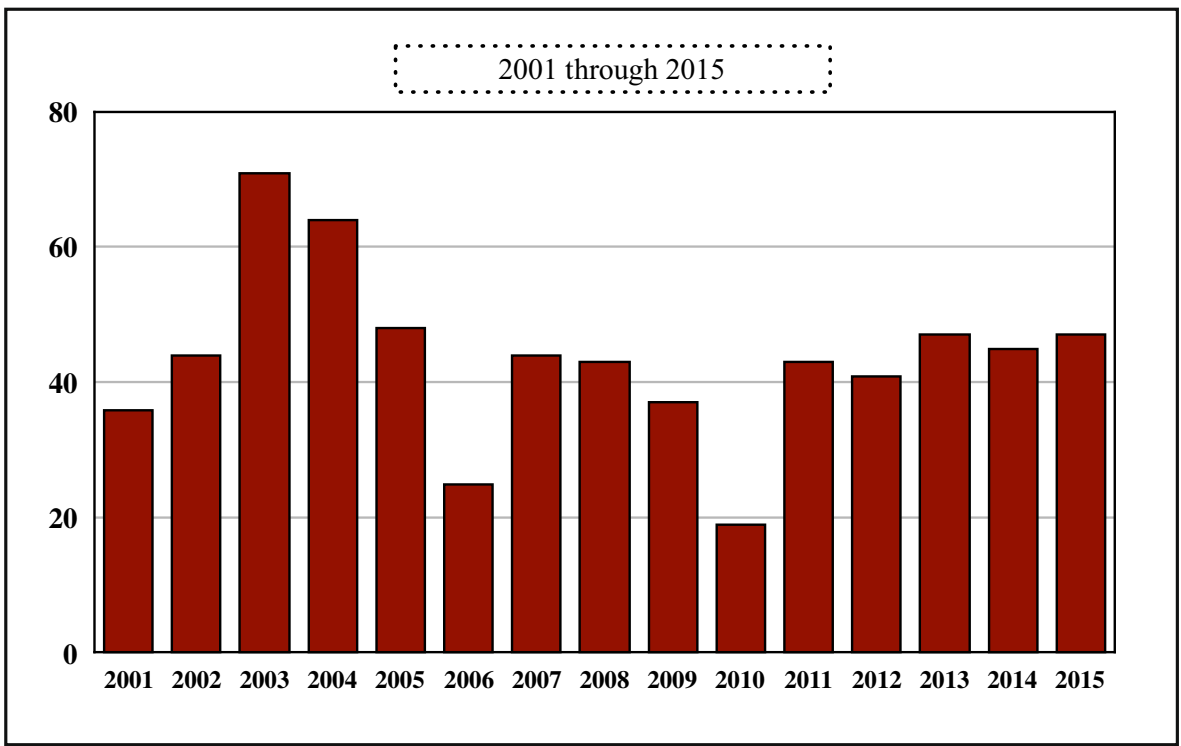

Fig. 1 Lawsuits by Year

cautionary warning but still faced subsequent litigation, with plaintiffs alleging that those warnings were insufficient. These univariates indicate that warning of impending negative earnings news does not prevent a lawsuit filing, as plaintiffs often argue that managers' warnings were too little or too late to be sufficient.

\subsection{Data}

After identifying and hand-collecting the litigation sample, we augment this dataset with financial statement data from Compustat, guidance and analyst forecast data from First Call and I/B/E/S, security price data from CRSP, and insider transaction data from Thomson Reuters. We begin this process by obtaining the report date of quarterly earnings announcements $(R D Q)$ for all lawsuit firms in Compustat for the eight quarters before and after the date of the lawsuit filing. To these firm-quarter observations, we add earnings guidance data from First Call's Company Issued Guidelines files and the earnings guidance data now offered by $\mathrm{I} / \mathrm{B} / \mathrm{E} / \mathrm{S} .^{10}$

We code variables that capture the frequency and timeliness of managers' guidance. First, we count the total number of pieces of guidance that the firm provided during that fiscal quarter ( $\left.G U I D A N C E \_C O U N T \_A L L\right)$, with zero signifying quarters in which managers did not provide any guidance. We code positive and negative guidance (POSITIVE_GUIDANCE_COUNT and NEGATIVE_GUIDANCE_COUNT) using

\footnotetext{
${ }^{10}$ First Call's guidance coverage ends in 2010. Although the current I/B/E/S earnings guidance dataset covers 2001 through 2014, some firms that were previously covered by First Call no longer appear in the I/B/E/S dataset. Consequently, we combine both datasets (removing duplicates) to maximize coverage. Chuk et al. (2013) find that the guidance data is more complete and less subject to coverage bias beginning after Reg FD. Consequently, we begin our lawsuit sample after Reg FD. We also confirm that all of our results are robust to removing the 56 lawsuits that have pre-lawsuit quarters occurring prior to Reg FD.
} 
analysts' prevailing estimates (following $\mathrm{I} / \mathrm{B} / \mathrm{E} / \mathrm{S}$ ); firm-quarters without positive or negative guidance are coded as zero. ${ }^{11}$ Using this approach, a revenue forecast and an earnings forecast provided on the same date are treated as separate pieces of guidance. Second, we count the number of unique days on which the firm provided guidance during that fiscal quarter (GUIDANCE_COUNT_DAYS). Using this second approach, concurrently provided forecasts are treated as a single guidance event. Finally, averaging over all guidance given during the quarter, we compute the mean number of days between the date of guidance and the end of the fiscal quarter ( GUIDANCE_HORIZON).

We gather additional disclosure data from RavenPack and the Thomson One StreetEvents database. In particular, we use RavenPack to identify the total number of firm-generated press releases in the quarter (PR_COUNT) but limit analysis to news items with a relevance score of 100 (i.e., where the entity was prominent in the news story). We classify the content of the press release as positive, negative, or neutral (POSITIVE_PR_COUNT, NEGATIVE_PR_COUNT, and NEUTRAL_PR_COUNT) based on the event sentiment score (ESS) in RavenPack, which is a granular score between 0 and 100 that represents the news sentiment for a given entity by measuring various proxies sampled from the news. An event with ESS greater than 50 represents a positive article, whereas one with ESS of less than 50 represents a negative article. Events with an ESS equal to 50 are considered neutral.

We use conference call transcripts obtained from Thomson One StreetEvents to develop our measures of conference call disclosure (CC_DISCLOSURE). We examine the content of conference calls (rather than the incidence of a call), because the vast majority of firms hold earnings conference calls after the passage of Reg FD. Although managers have some discretion over the tone they convey in an earnings call, the tone is largely dictated by the firm's quarterly earnings performance and the content of the questions asked by analysts. Thus, in contrast to earnings forecasts, which managers can choose to provide, depending upon the information contained therein, managers cannot avoid hosting a call depending on the nature of the news to be discussed. As such, our tests focus on the level of disclosure and responsiveness of managers to analyst questions during the conference call. For each sued firm, we obtain transcripts from events occurring during the eight-quarter pre- and post-lawsuit periods used in our main firm-quarter sample tests. We limit our earnings conference call collection to firms whose lawsuit occurred in 2003 or later, which allows the pre-sued period to occur in the post-Reg-FD timeframe. We then match the date of each recorded transcript to the earnings release date in Compustat to identify quarterly earnings calls. Using a Python script, we then capture and parse the text of each call transcript to identify key variables related to the call, including the words and proportion of the call in the opening (scripted) monologue of the call presented by management (Mono words, Mono \%), the number of questions asked by analysts during the Q\&A session (\#Qs), and the mean word length of management responses to such questions (Response per $Q$ ).

Next, we collect analyst forecast data from $\mathrm{I} / \mathrm{B} / \mathrm{E} / \mathrm{S}$, using the unadjusted, detail file three days prior to each earnings announcement. From this file, we derive the number of analyst forecasts (NUMEST), conditional on the forecast being no more than 90 days

\footnotetext{
${ }^{11}$ All results are robust to coding positive and negative guidance following the approach developed by Rogers and Van Buskirk (2013).
} 
old (i.e., nonstale); the median nonstale analyst forecast; and the standard deviation of nonstale analyst forecasts (DISPERSION). We measure each quarter's earnings surprise (SURPRISE) as the reported actual earnings minus the most recent median analyst estimates, deflated by stock price three trading days prior to the earnings release date. That is, we examine the typical standardized unexpected earnings surprise. Following Rogers and Van Buskirk (2013), we create indicator variables for positive earnings surprises ( $P$ SURPRISE equals one if SURPRISE $>+0.0001)$ and for negative earnings surprises (N_SURPRISE equals one if SURPRISE $<-0.0001)$. In addition, we code an indicator variable for firm quarters where the firm reports negative earnings (LOSS). To capture the recent history of earnings surprises, we compute the proportion of the four prior quarters that SURPRISE was nonnegative, that is, the proportion of quarters the firm met or beat the median analyst forecast $(P R O P M B)$.

In addition to actual and forecasted earnings information, we collect share price, return, number of shares outstanding, and volume data from CRSP. We use these data to compute the market value of a firm's equity each quarter (MVE), the 90-day return ending three days prior to the earnings release date (PRIOR_RET), and the standard deviation of daily returns over that 90 -day period (VOLATILITY).

We also gather insider trading data from the Thomson Reuters Stock Transactions file. In constructing our trading measures, we concentrate on the behavior of directors and officers, consistent with prior work (e.g., Johnson et al. 2007; Li et al. 2016). This focuses our attention on the trading decisions of those insiders who are most likely to be aware of impending earnings news and most likely to be in a position to influence the firm's disclosures. To further concentrate on the trading of individuals most central to disclosure choices, we restrict our measure of insider trading to actions of just the CEO and CFO. ${ }^{12}$

We fully define all the variables used in our analyses in the appendix. Table 2 displays descriptive statistics for the quarter immediately prior to the lawsuit filing for each of the 654 lawsuit firms. As shown, the median lawsuit firm has a market capitalization (MVE) of $\$ 970$ million, is followed by six analysts (NUMEST), has met or beat analysts' estimates in three of the prior four quarters, and reported a $0.33 \%$ return-on-assets $(R O A)$ while earning a $-8.3 \%$ return in the quarter leading up to the lawsuit filing. ${ }^{13}$

\subsection{Univariate analyses}

Because our predictions focus on changes in managers' disclosure behavior in response to litigation, we begin by comparing measures of guidance activity in the eight quarters before (i.e., POST-SUIT =0) to the eight quarters after (i.e., POST-SUIT =1) the lawsuit filing. Within these measures, we separate the forecasts based on the sign of the forecast news (negative, neutral, and positive). As shown in Table 3, the evidence supports the notion that the sign of disclosure matters: positive (negative) guidance occurs less (more) frequently in the post-sued period, measured in both

\footnotetext{
$\overline{12}$ Results are robust if we do not limit analysis to the trades of just the CEO and CFO.

${ }^{13}$ As noted earlier, litigation for the median firm in our sample takes many years to resolve. At the same time, descriptive statistics presented in Table 2 indicate that more than one quarter of all lawsuit firms replace their CEO in the year following the lawsuit filing. In untabulated analyses, we find that all of our main inferences hold, regardless of whether the firm appoints a new CEO in the one-year, two-year or three-year window following the lawsuit filing.
} 
Table 2 Descriptive Statistics

\begin{tabular}{lccc}
\hline & Mean & Median & St. dev. \\
\hline MVE (\$ millions) & $\$ 6,046$ & $\$ 970$ & $\$ 18,353$ \\
ASSETS (\$ millions) & $\$ 25,360$ & $\$ 1,048$ & $\$ 150,989$ \\
GUIDER & 0.739 & 1 & 0.440 \\
GUIDE_CQTR & 0.358 & 0 & 0.480 \\
P_SURPRISE & 0.434 & 0 & 0.496 \\
N_SURPRISE & 0.434 & 0 & 0.496 \\
LOSS & 0.291 & 0 & 0.454 \\
DISPERSION & 0.047 & 0.018 & 0.085 \\
PRIOR_RET & $-8.9 \%$ & $-8.3 \%$ & $31.8 \%$ \\
NUMEST & 8.2 & 6 & 6.9 \\
PROPMB & 0.689 & 0.75 & 0.317 \\
VOLATILITY & 0.039 & 0.032 & 0.026 \\
LITIGATION_RISK & $0.52 \%$ & $0.35 \%$ & $0.57 \%$ \\
NEWS_ITEMS & 27.1 & 20 & 31.7 \\
$\Delta$ LIT_NEWS_ITEMS & +3.63 & +3 & +3.54 \\
SALES_ALL & $0.19 \%$ & $0.33 \%$ & $0.93 \%$ \\
CEO_TURN & 0.284 & $0.98 \%$ & 0.451 \\
ROA & $-0.47 \%$ \\
\hline
\end{tabular}

Table 2 provides descriptive statistics for the 654 lawsuit firms in the fiscal quarter immediately prior to the quarter in which the firm was sued. MVE is the market value of the firm's equity (price multiplied by shares outstanding) measured three days before the report date of quarterly earnings. ASSETS is firm's total reported assets at the beginning of the quarter. GUIDER is an indicator variable set to 1 if the firm provided guidance in the two years prior to the lawsuit filing. GUIDE_CQTR is an indicator variable set to 1 if the firm previously provided earnings guidance for the current quarter's earnings. P_SURPRISE and N_SURPRISE are indicator variables set to 1 if the earnings surprise for the quarter (defined as actual earnings minus the prevailing median analyst estimate, deflated by stock price three trading days prior to the report date of quarterly earnings) is greater than +0.0001 or less than -0.0001 , respectively. LOSS is an indicator variable set to 1 if actual earnings is negative. DISPERSION is the standard deviation of prevailing analyst estimates for the current period's earnings. PRIOR_RET is the 90-day return ending three days prior to the earnings release date. NUMEST is the number of analyst earnings forecasts for that quarter that are not more than 90 days old. PROPMB is the proportion of the previous four quarters that the firm's reported earnings met or exceeded analysts' prevailing median consensus estimates. VOLATILITY is the standard deviation of daily stock returns over the 90-day period ending three days prior to earnings release. LITIGATION RISK is the ex ante probability estimate of the likelihood that the firm will be the subject of 10b-5 litigation in the next quarter, based on the model of eq. (3) of Kim and Skinner (2012). NEWS ITEMS is the number of Capital IQ Key Development news items not relating to litigation (i.e., excluding Item \#25) during days $[-10,+180]$, relative to the lawsuit date. $\triangle$ LIT NEWS ITEMS is the number of Capital IQ Key Development news items relating to litigation (Item \#25) during days $[-10,+180]$, relative to the lawsuit date, minus the number of items over the same period one year prior. SALES_ALL is the total dollar value of insider sales during the quarter, scaled by the beginning market value of equity. CEO TURN is an indicator variable set to 1 if the firm appoints a new CEO in the year following the lawsuit filing. ROA is the return on assets, defined as net income divided by beginning total assets.

GUIDANCE_COUNT_ALL and GUIDANCE_COUNT_DAYS. Further, the GUIDANCE_HORIZON for negative (positive) guidance increases (decreases) in the post-sued period. At the same time, press release activity (of any sentiment) generally increases in the post-sued period. Conference call metrics also change after a lawsuit: 
the opening monologue segment (both in absolute numbers and as a percentage of the total words in the call) increases. The number of questions fielded decreases; however, the number of words used in response to each question does not decrease, suggesting that overall responsiveness does not change. ${ }^{14}$ Turning our attention to indirect measures of information flow pre- and post-lawsuit, we find that signed forecast and analyst error do not significantly change, while the likelihood of a significant beat (which we define as a signed analyst surprise $>+0.01$ ) increases.

Collectively, these univariate findings contradict the notion that litigation causes managers to revise their beliefs about the costs and benefits of their current level of disclosure, regardless of the sign of the news. Instead, they provide initial support for the notion that managers respond to litigation by reducing the frequency and timeliness of their positive and neutral news forecasts while increasing the frequency and timeliness of their negative news forecasts. In our upcoming multivariate tests, we examine changes in managers' disclosure behavior surrounding lawsuit filings (1) after controlling for various determinants of managers' disclosure decisions documented by prior work and (2) as compared to corresponding changes in disclosure for a group of propensity-matched control firms that were not sued.

\subsection{Propensity-matched control sample}

We propensity-match our lawsuit firms to suitable control firms in the year prior to the lawsuit filing based on the litigation risk model as detailed by Kim and Skinner (2012, Eq. 3), which takes into account industry membership (HIGHLIT_FPS), firm size (ASSETS), performance (RETURN and SALES_GROWTH), skewness of returns (SKEWNESS), return volatility (VOLATILITY), and share turnover (TURNOVER). We augment this litigation risk model to include insider sales (CEOCFO_SALES_ALL) to assemble a propensity-matched sample of control firms that faced similar litigation risk (Billings and Cedergren 2015). Specifically, we estimate our augmented Kim and Skinner (2012) logistic regression model over a population of 159,399 firm-quarters during our sample period, and each sued firm's lawsuit quarter is then matched without replacement to a nonsued firm-quarter using nearest neighbor matching of the lawsuit fitted probability. The matched firm-quarter serves as the pseudo-lawsuit quarter for the matched control firm, with the eight quarters before and after the pseudo-lawsuit quarter serving as the matched control firm's pre-sued and post-sued periods, respectively.

Table 4 provides descriptive statistics for the 654 lawsuit firms $(S U E D=1)$ and 654 control firms $(S U E D=0)$. Our propensity-matching approach leads us to identify a suitable group of similarly situated control firms in terms of litigation risk, with all but one of the covariates (VOLATILITY) showing no significant differences between the sued and nonsued group. (We further control for volatility in all our regression specifications.) Further, we detect no differences in overall guidance activity in the two years leading up to the lawsuit filing. In our upcoming multivariate tests, we address any potential lingering disparities with the inclusion of additional control variables, including measures of prior disclosure behavior.

\footnotetext{
${ }_{14}$ The number of questions during the conference call likely decreases because conference calls are scheduled for a certain duration. As the opening monologue increases, there remains relatively less time for questions.
} 
Table 3 Univariate Changes in Disclosure Behavior

\begin{tabular}{|c|c|c|c|c|c|c|}
\hline & \multicolumn{2}{|c|}{ Pre-suit $(n=4,168)$} & \multicolumn{2}{|c|}{ Post-suit $(n=4,182)$} & \multicolumn{2}{|c|}{ Differences } \\
\hline & Mean & Median & Mean & Median & Mean & Median \\
\hline \multicolumn{7}{|l|}{ GUIDANCE_COUNT_ALL } \\
\hline Negative & 0.495 & 0 & 0.635 & 0 & $+0.140 \bullet \bullet$ & $0 \bullet \bullet$ \\
\hline Neutral & 0.908 & 0 & 0.835 & 0 & $-0.073 \bullet \bullet$ & 0 \\
\hline Positive & 0.448 & 0 & 0.356 & 0 & $-0.093 \bullet \bullet$ & $0 \bullet \bullet$ \\
\hline \multicolumn{7}{|c|}{ GUIDANCE_COUNT_DAYS } \\
\hline Negative & 0.250 & 0 & 0.338 & 0 & $+0.087 \bullet \bullet$ & $0 \bullet \bullet$ \\
\hline Neutral & 0.458 & 0 & 0.458 & 0 & -0.001 & 0 \\
\hline Positive & 0.252 & 0 & 0.232 & 0 & $-0.019 \bullet$ & 0 \\
\hline \multicolumn{7}{|l|}{ GUIDANCE_HORIZON } \\
\hline Negative & 32.6 & 0 & 37.9 & 0 & $+5.3 \bullet \bullet$ & $0 \bullet \bullet$ \\
\hline Neutral & 60.3 & 0 & 56.7 & 0 & -3.6 & 0 \\
\hline Positive & 40.5 & 0 & 34.8 & 0 & $-5.6 \bullet \bullet$ & $0 \bullet \bullet$ \\
\hline \multicolumn{7}{|l|}{$P R \_C O U N T$} \\
\hline Negative & 1.35 & 0 & 2.31 & 0 & $+0.96 \bullet \bullet \bullet$ & $0 \bullet \bullet$ \\
\hline Neutral & 5.72 & 5 & 6.92 & 6 & $+1.20 \bullet$ & $+1 \cdots$ \\
\hline Positive & 8.83 & 3 & 9.82 & 4 & +0.99 & $+1 \bullet \bullet$ \\
\hline \multicolumn{7}{|l|}{ Conference calls } \\
\hline Mono words & 3,986 & 3,397 & 4,126 & 3,416 & $+140 \bullet \bullet$ & $+19 \bullet$ \\
\hline Mono \% & $51.5 \%$ & $45.1 \%$ & $55.4 \%$ & $48.1 \%$ & $+3.9 \%$ & $+3.0 \%$ \\
\hline \# Qs & 19.6 & 19 & 17.0 & 16 & $-2.5 \bullet \bullet$ & $-3 \bullet \bullet$ \\
\hline Response per Q & 173.2 & 127.8 & 187.6 & 128.4 & +14.3 & +0.6 \\
\hline \multicolumn{7}{|l|}{ Information Environment } \\
\hline Signed forecast error & 0.001 & 0 & -0.001 & 0 & -0.002 & 0 \\
\hline Unsigned forecast error & 0.030 & 0.005 & 0.068 & 0.009 & $+0.038 \bullet \bullet$ & $+0.004 \bullet \bullet \bullet$ \\
\hline SURPRISE & -0.002 & 0.000 & -0.003 & 0.001 & -0.001 & $+0.000 \bullet \bullet$ \\
\hline P_SURPRISE & 0.587 & 1 & 0.575 & 1 & -0.012 & 0 \\
\hline BEAT & 0.048 & 0 & 0.098 & 0 & $+0.049 \bullet \bullet$ & $0 \bullet \bullet$ \\
\hline
\end{tabular}

This table provides univariate changes in disclosure behavior in the eight quarters before and after the lawsuit filing.

Guidance - GUIDANCE_COUNT_ALL is the total number of pieces of guidance (earnings or nonearnings) that the firm provided during that fiscal quarter. GUIDANCE_COUNT_DAYS is the number of unique days on which the firm provided guidance during that fiscal quarter. GUIDANCE_HORIZON is the mean (for all guidance given during the quarter) number of days between the date of guidance and the end of the fiscal quarter being guided. We compute each of these guidance-related measures based on the sign of the forecast (negative, neutral, or positive) using the I/B/E/S-provided classification, which is based on prevailing analysts' forecasts.

Press releases - PR_COUNT is the total number of press releases about the firm in the quarter appearing the RavenPack database, among items with a relevance score of 100. Press releases with an event sentiment score of less than 50, equal to 50, and greater than 50 are classified as negative, neutral, and positive, respectively Conference calls - MonoWords is the total number of words spoken in the opening monologue session of the conference call. Mono \% is the number of words in the opening monologue as a proportion of the total words spoken by all parties in the entirety of the conference call. \# Qs is the total number of analyst questions fielded 
by managers during the conference call. Response per $\mathrm{Q}$ is the average number of words spoken in response to each question fielded.

Indirect measures - Signed forecast error is the difference between actual earnings minus the prevailing management estimate (based on the last available forecast during the quarter). Unsigned forecast error is the absolute value of the signed forecast error. SURPRISE is actual earnings minus the prevailing median analyst estimate, deflated by stock price three trading days prior to the report date of quarterly earnings. P_SURPRISE is an indicator set to 1 if SURPRISE is greater than +0.0001 . BEAT is a sizable positive earnings surprise and is an indicator set to 1 if SURPRISE is greater than +0.01

Table 4 Propensity-Matched Control Sample

\begin{tabular}{|c|c|c|c|c|}
\hline & Non-sued firms & Sued firms & \multicolumn{2}{|c|}{ Difference ( $t$-stat) } \\
\hline \multicolumn{5}{|l|}{ Matching covariates } \\
\hline HIGHLIT_FPS & 0.468 & 0.442 & -0.026 & 0.94 \\
\hline Log ASSETS & 7.183 & 7.267 & 0.084 & 0.75 \\
\hline SALES_GROWTH & $-0.17 \%$ & $1.34 \%$ & 0.015 & 1.16 \\
\hline RETURN $[-4 Q,-1 Q]$ & 0.023 & 0.029 & 0.006 & 0.12 \\
\hline VOLATILITY $[-4 \mathrm{Q},-1 \mathrm{Q}]$ & 0.040 & 0.037 & -0.003 & 2.22 \\
\hline SKEWNESS $[-4 \mathrm{Q},-1 \mathrm{Q}]$ & -0.137 & -0.297 & -0.160 & 1.60 \\
\hline VOLUME $[-4 Q,-1 Q]$ & 0.015 & 0.016 & 0.001 & 1.50 \\
\hline RETURN $[-8 \mathrm{Q},-5 \mathrm{Q}]$ & 0.265 & 0.374 & 0.109 & 1.53 \\
\hline CEOCFO_SALES_ALL $[-4 \mathrm{Q},-1 \mathrm{Q}]$ & $0.27 \%$ & $0.25 \%$ & 0.000 & 0.26 \\
\hline \multicolumn{5}{|l|}{$\underline{\text { Guidance }}$} \\
\hline GUIDANCE_COUNT_DAYS $[-8 \mathrm{Q},-5 \mathrm{Q}]$ & 0.963 & 0.918 & -0.045 & 1.08 \\
\hline GUIDANCE_COUNT_DAYS $[-4 \mathrm{Q},-1 \mathrm{Q}]$ & 1.008 & 0.995 & -0.013 & 0.34 \\
\hline \multicolumn{5}{|l|}{ Performance } \\
\hline $\mathrm{ROA}[-8 \mathrm{Q},-5 \mathrm{Q}]$ & $0.8 \%$ & $1.8 \%$ & $1.0 \%$ & 0.88 \\
\hline $\mathrm{ROA}[-4 \mathrm{Q},-1 \mathrm{Q}]$ & $-0.3 \%$ & $2.0 \%$ & $2.4 \%$ & 1.57 \\
\hline $\mathrm{ROA}[+1 \mathrm{Q},+4 \mathrm{Q}]$ & $-2.0 \%$ & $-6.0 \%$ & $-4.0 \%$ & 2.67 \\
\hline $\mathrm{ROA}[+5 \mathrm{Q},+8 \mathrm{Q}]$ & $-0.1 \%$ & $-0.9 \%$ & $-0.8 \%$ & 0.79 \\
\hline RETURN [-8Q, $-5 \mathrm{Q}]$ & $26.5 \%$ & $37.4 \%$ & $10.9 \%$ & 1.53 \\
\hline RETURN $[-4 Q,-1 Q]$ & $2.3 \%$ & $2.9 \%$ & $0.6 \%$ & 0.12 \\
\hline RETURN [+1Q, +4Q] & $17.5 \%$ & $-0.9 \%$ & $-18.5 \%$ & 5.18 \\
\hline RETURN [+5Q, +8Q] & $20.0 \%$ & $18.5 \%$ & $-1.5 \%$ & 0.42 \\
\hline
\end{tabular}

This table compares the treatment sample of sued firms and control sample of nonsued firms. FPS is an indicator variable set to 1 if the firm operates in a "high-litigation" industry, as defined by Francis et al. (1994) and employed by Kim and Skinner (2012). Log ASSETS is the log of total assets at the end of the quarter. SALES_GROWTH is the firm's percentage change in sales for the quarter. RETURN [-4Q, $-1 \mathrm{Q}]$ and RETURN $[-8 \mathrm{Q},-5 \mathrm{Q}]$ are the firm's return from quarter $t-4$ through $t-1$ and from $t-8$ through $t-5$, respectively. VOLATILITY $[-4 \mathrm{Q},-1 \mathrm{Q}]$ is the daily return volatility from quarter $t-4$ through $t-1$. SKEWNESS $[-4 \mathrm{Q},-1 \mathrm{Q}]$ is the daily return skewness from quarter $t-4$ through $t-1$. VOLUME [-4Q, $-1 \mathrm{Q}]$ is the total share turnover from quarter $t-4$ through $t-1$. CEOCFO_SALES_ALL [-4Q, $-1 \mathrm{Q}]$ is the total insider sales by the CEO and CFO from quarter $t-4$ through $t-1$ scaled by market value of equity. GUIDANCE_COUNT_DAYS is the total number of pieces of guidance (earnings or non-earnings) that the firm provided during that fiscal quarter. ROA is net income divided by beginning total assets 
We also tabulate the trend in measures of firm performance in the seventeen quarters centered on the lawsuit filing. As shown in Table 4, we do not detect significant differences in ROA or stock performance during the eight quarters prior to the lawsuit filing. Thus our matching procedure appears to have selected similarly situated control firms in terms of performance prior to the filing of the lawsuit. In terms of post-lawsuit performance, not surprisingly, we do detect differences in the quarters immediately following the lawsuit filing. Yet no significant differences remain beginning four quarters after the lawsuit filing.

To further examine comparative trends in performance, we plot the quarterly measures of ROA for both the lawsuit and control firms in Fig. 2. This figure highlights that both the lawsuit and control firms experience a deteriorating trend in ROA in the quarters leading up to the (pseudo-) lawsuit date (i.e., quarter 0 ). This negative trend, however, reverses by quarter +1 , when ROA trends upward in the post-lawsuit period both for the lawsuit and control firms.

Collectively, this evidence helps quiet concerns that the changes in disclosure that we document stem from differentially worse financial situations between the lawsuit and control firms ex ante. Nonetheless, while the evidence in Table 4 and Fig. 2 suggests that the lawsuit and control firms are well-matched before the lawsuit filing, differences in firm performance do emerge in the year immediately following the lawsuit. This highlights the need for strong controls for differences in financial condition in our analyses. Consequently, we include measures of firm performance (returns, ROA, and sales growth) as controls in our upcoming multivariate tests.

In addition, we perform a battery of untabulated robustness tests to address the concern that differential ex post performance explains the changes in disclosure we observe. First, we re-estimate the main analyses including controls for differential performance in the

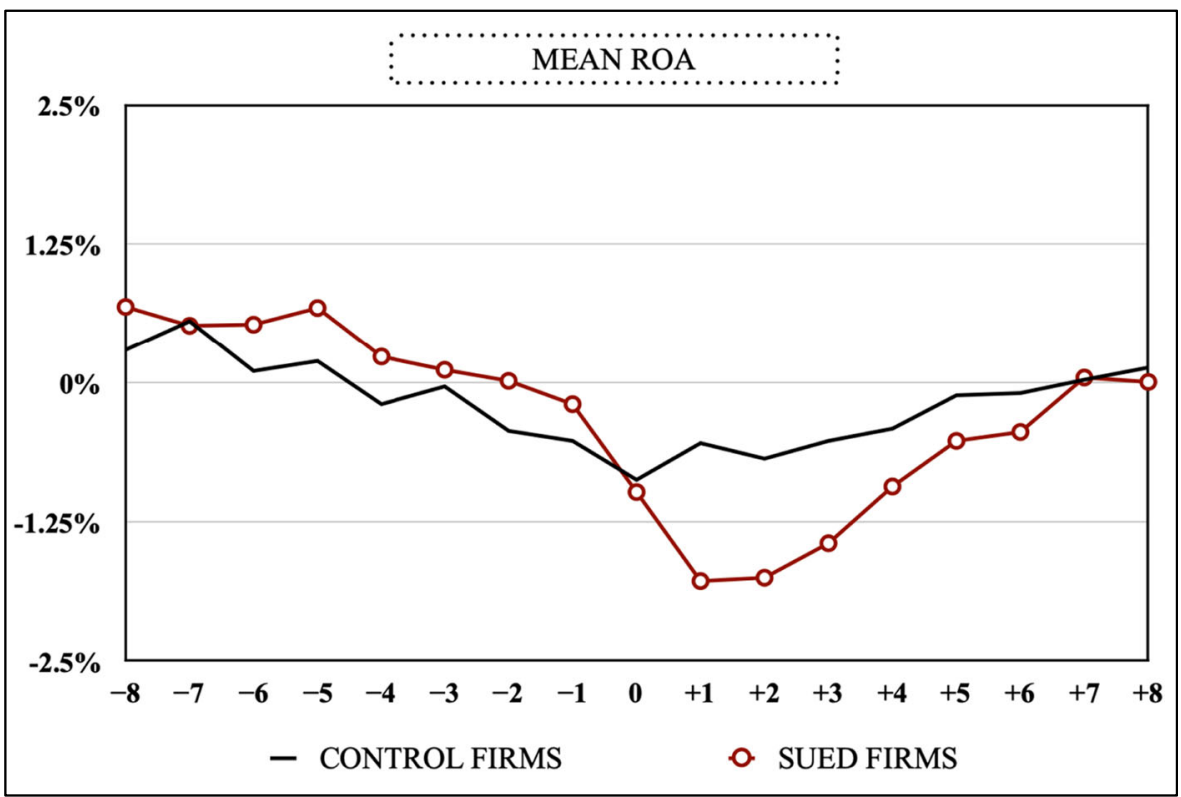

Fig. 2 Trend Analysis Quarters [ $-8,+8]$ Relative to Lawsuit. This figure presents a trend analysis of ROA in the 17-quarter period centered on the quarter in which the firm was sued (or the pseudo-lawsuit quarter for control firms) 
forecast-quarter. To do so, we consider a number of variations: (1) we control for differential ROA, calculated as the ROA of the sued (nonsued) firm minus the ROA of the nonsued (sued) firm in the corresponding quarter, relative to the lawsuit quarter, and differential return performance (calculated in an analogous fashion as differential ROA performance); (2) we control for differential year-over-year quarterly change in ROA (again calculated in an analogous fashion); (3) we control for the absolute value of the differential ROA and the differential return performance in the forecast quarter; (4) we include an indicator variable to control for instances where the differential ROA or differential return performance exceeded $5 \%$ in the forecast quarter. Second, we reestimate the main analyses (as well as all of the robustness tests described above) using alternative control samples matched based on ex post performance alone. Finally, we also re-estimate the main analyses using a propensity-matched sample that considers ex post performance along with our original roster of matching criteria. Our main results remain robust across all of these additional specifications, and, in fact, the coefficient estimates and $t$-statistics for our variables of interest remain virtually unchanged.

\section{Results}

\subsection{Research design}

Using the propensity-matched nonsued firms as a benchmark, we begin by examining whether firms reduce their overall level of disclosure after lawsuit filings. To do so, we estimate the following regression model that builds on the model of Rogers and Van Buskirk (2013) and augmented by Billings et al. (2015), as follows.

$$
\begin{aligned}
& \text { DISCLOSURE }=\beta_{0}+\beta_{1}(\mathrm{SUED} \times \mathrm{POST}-\mathrm{SUIT})+\beta_{2}(\mathrm{POST}-\mathrm{SUIT}) \\
& +\beta_{3}(\text { SUED })+\beta_{4}(\text { GUIDE_CQTR })+\beta_{5}(\text { GUIDE_PRIOR })+\beta_{6}(\text { P_SURPRISE }) \\
& +\beta_{7} \text { (N_SURPRISE) }+\beta_{8}(\mid \text { SURPRISE } \mid)+\beta_{9}(\text { LOSS })+\beta_{10}(\text { DISPERSION }) \\
& +\beta_{11}(\text { PRIOR_RET })+\beta_{12}(\text { Log_MVE })+\beta_{13}(\text { Log_NUMEST })+\beta_{14}(\text { PROPMB }) \\
& +\beta_{15}(\text { VOLATILITY })+\beta_{16}(\mathrm{ROA})+\beta_{17}(\text { CEOCFO_SALES_ALL })+\varepsilon \text {. }
\end{aligned}
$$

DISCLOSURE takes on the different disclosure variables as delineated in Section 2 when discussing the univariate results of Table 3.

Consistent with Rogers and Van Buskirk (2013), we expect that current-quarter guidance increases with past guidance. Accordingly, the inclusion of both GUIDE_CQTR and GUIDE_PRIOR allows us to focus on the factors associated with the decision to guide in the current quarter - as opposed to examining the factors that determine firms' decisions to commit to an overall practice of issuing guidance. ${ }^{15}$

Following Rogers and Van Buskirk (2013), we control for the current quarter's earnings news (P_SURPRISE, N_SURPRISE, |SURPRISE|, and LOSS), the information environment

\footnotetext{
${ }^{15}$ Not surprisingly, GUIDE_CQTR and GUIDE_PRIOR are highly correlated $(0.389, p<0.001$ Spearman correlation in the full sample of firm-quarter observations). Following Rogers and Van Buskirk (2013), we include both in our tabulated regressions. All of our results remain when we re-estimate our regressions, excluding either GUIDE_CQTR or GUIDE_PRIOR.
} 
of the firm (DISPERSION, Log_MVE, and Log_NUMEST), and recent performance (PRIOR_RET and PROPMB). Consistent with Billings and Cedergren (2015), Billings et al. (2015), and Li et al. (2016), we also include controls for forecast difficulty (VOLATILITY) and the presence of "disclose-or-abstain" insider trading incentives (CEOCFO_SALES_ALL).

\subsection{Do managers reduce overall guidance in response to litigation?}

Our first multivariate test examines changes in guidance behavior surrounding litigation. To do so, we estimate Eq. (1) where GUIDANCE_COUNT ALL serves as the dependent variable. If lawsuit managers respond to litigation with reduced disclosure, as compared to the propensity-matched control firms, we expect to observe a negative coefficient for the interaction $S U E D \times P O S T-S U I T$. We report results of this regression in Table 5 .

In column [1], we examine GUIDANCE_COUNT_ALL for the full lawsuit sample of sued and matched firms. Consistent with Rogers and Van Buskirk (2009), our evidence indicates that lawsuit managers reduce the overall level of guidance in response to a shareholder lawsuit, as compared to similarly situated matched firms. ${ }^{16}$ With respect to control variables, our conclusions are generally consistent with expectations. Most notably, prior guidance activity (GUIDE_CQTR and GUIDE_PRIOR) predicts current-quarter guidance frequency, while the guidance frequency falls with forecast difficulty (DISPERSION).

The result strengthens when we focus on nondismissed (i.e., settled) lawsuits. Comparing the dismissed lawsuit sample (column 3) to the nondismissed lawsuit subsample (column 2), the statistical significance and the magnitude of the coefficient increases considerably (from -0.046 to -0.079 ). While the litigation outcome is not known to the firm at the time of the lawsuit filing, managers are likely to have an estimate as to the strength of the case against them early on and form a belief about the likelihood of dismissal. As such, the partition between dismissed versus nondismissed likely identifies variation in the severity (treatment effect) of litigation. That is, the dismissed cases represent the less costly lawsuits that resolve more quickly. Thus, consistent with this notion and with Rogers and Van Buskirk (2009), we observe the effect of litigation on overall disclosure is stronger within the nondismissed, more costly lawsuits. ${ }^{17}$

Relatedly, Cutler et al. (2019) demonstrate a link between increased disclosure during the class period and the likelihood of nondismissal (i.e., settlement). In relation to our findings, one potential interpretation of this negative relation between disclosure during the class period and severity of the lawsuit is that litigation may cause managers to view disclosure as costly. Yet it is important to note that Cutler et al. use the dismissed versus nondismissed (settled) indicator as an outcome variable, suggesting that settlement is a costly outcome. In contrast, Rogers and Van Buskirk (2009) use the

\footnotetext{
${ }^{16}$ Rogers and Van Buskirk (2009) also consider forecast precision in their tests. Chuk et al. (2013) discuss the possible incompleteness of the guidance data (previously provided by First Call and now maintained by I/B/E/S) and, in so doing, conclude that the guidance data is unreliable and cannot be used to measure qualitative guidance. Consequently, we follow more recent studies that begin analysis after Reg FD and that limit the study of guidance data to quantitative forecasts - as Chuk et al. show that the guidance data is more complete and less subject to bias for quantitative forecasts after Reg FD.

${ }^{17}$ Limiting analysis to the 301 settled lawsuits, we also find that the lawsuits with above-median settlements are associated with stronger overall reductions in disclosure.
} 
Table 5 Do Managers Adopt a More Conservative Disclosure Strategy in Response to Litigation?

Panel A: All guidance

Dependent variable $=\log ($ GUIDANCE_COUNT $)$ Coefficient effect ( $t$-statistic below)

\section{All lawsuits}

[1]

SUED $\times$

POST-SUIT

POST-SUIT

SUED

GUIDE_CQTR

GUIDE_PRIOR

P_SURPRISE

N_SURPRISE

|SURPRISE|

LOSS

DISPERSION

PRIOR_RET

Log(MVE)

Log(NUMEST)

PROPMB

VOLATILITY

ROA

n

R-squared
$-0.061 \bullet$

$-3.84$

$-0.019 \bullet$

$-1.71$

$0.058 \bullet \bullet$

5.30

$0.560 \bullet \bullet$

59.04

$0.621 \bullet \bullet$

69.24

$0.050 \bullet \bullet$

3.66

$-0.001$

$-0.09$

$-0.298 \bullet \bullet$

$-3.65$

-0.022 •

$-1.83$

-0.338 •.•

$-7.51$

-0.027 •

$-1.76$

$-0.015 \bullet$

$-4.69$

$0.109 \bullet \bullet$

16.34

$0.175 \bullet \bullet$

11.86

0.424 •

1.90

$0.278 \bullet \bullet$

4.31

17,999

$51.8 \%$
Nondismissed lawsuits

[2]

$-0.079 \bullet . \bullet$

$-3.42$

$-0.022$

$-1.39$

$0.061 \bullet . \bullet$

3.83

$0.574 \bullet \bullet$

41.04

$0.627 \bullet \bullet$

48.18

$0.039 \bullet \bullet$

2.02

$-0.007$

$-0.33$

$-0.278 \bullet . \bullet$

$-2.64$

$-0.026$

$-1.54$

$-0.467 \bullet \bullet$

$-6.54$

$-0.044 \bullet$

$-1.97$

$-0.017 \bullet \bullet$

$-3.59$

$0.094 \bullet \bullet$

9.63

$0.092 \bullet$

4.39

0.150

0.49

$0.247 \bullet \bullet$

2.87

8312

$52.0 \%$
Dismissed lawsuits [3] $-0.046 \bullet \bullet$ $-2.08$ $-0.016$

$-1.03$

$0.052 \bullet \bullet$

3.42

$0.548 \bullet$

42.53

$0.611 \bullet$

49.39

$0.058 \bullet \bullet$

3.06

0.004

0.20

$-0.319 \bullet$

$-2.45$

$-0.015$

$-0.90$

$-0.244 \bullet \bullet$

$-4.19$

$-0.014$

$-0.65$

$-0.013 \cdots$

$-3.11$

$0.121 \bullet \bullet$

13.36

$0.248 \bullet . \bullet$

11.93

$0.706 \bullet$

2.19

$0.303 \bullet \bullet$

3.13

9687

$51.8 \%$ 
Table 5 (continued)

Panel B: Positive versus Negative Guidance

\section{Dependent variable $=\mathbf{L o g} \quad$ Dependent variable $=\mathbf{L o g}$ \\ GUIDANCE_COUNT Coefficient effect GUIDANCE_HORIZON Coefficient effect (t-stat below)}

Positive
GUIDANCE
COUNT

[1]

Negative
GUIDANCE
COUNT

[2]

$0.024 \cdots$

2.68

$-0.006$

$-0.90$

$-0.013 \cdot \bullet$

$-2.01$

17,999

$19.2 \%$

\section{Positive GUIDANCE \\ HORIZON}

[3]

-0.203 ••

$-2.15$

$-0.096$

$-1.42$

$-0.090$

$-1.37$

10,216

$7.2 \%$

\section{Negative \\ GUIDANCE \\ HORIZON}

[4]

0.171 •

$-0.057$

$-0.88$

$-0.006$

$-0.10$

10,216

$8.0 \%$

Controls included: Year effects, insider trading measures, GUIDE_CQTR, GUIDE_PRIOR, P_SURPRISE, N_SURPRISE, SURPRISE, LOSS, DISPERSION, PRIOR_RET, Log(MVE), Log(NUMEST), PROPMB, VOLATILITY, SALES, ROA.

This analysis examines guidance behavior before and after the lawsuit for the 654 sued firms and the propensity-matched nonsued firms in the eight quarters before and after the filing of the lawsuit. Panel A presents the overall change in guidance, while Panel B takes into account the sign of the guidance. The symbols $\cdots, \cdots, \bullet$ denote significance at the $1 \%, 5 \%$, and $10 \%$ levels, respectively, for two-tailed tests. The dependent variable Log GUIDANCE COUNT is the log of the total number of pieces of guidance given during the fiscal quarter. The sign of the forecast (negative or positive) is from the $\mathrm{I} / \mathrm{B} / \mathrm{E} / \mathrm{S}$-provided classification, which is based on prevailing analysts' forecasts. The dependent variable Log GUIDANCE_HORIZON is the mean (for all guidance given during the quarter) number of days between the date of guidance and the end of the fiscal quarter being guided. SUED is an indicator set to 1 for treatment (i.e., sued firms). POST-SUIT is an indicator set to 1 if the firm-quarter was after the lawsuit (or pseudolawsuit for control firms). GUIDE_CQTR is an indicator variable set to 1 if the firm previously provided earnings guidance for the current quarter's earnings. GUIDE PRIOR is an indicator variable set to 1 if the firm provided earnings guidance relating to the prior quarter's reported earnings. P_SURPRISE and N_SURPRISE are indicator variables set to 1 if the earnings surprise for the quarter is greater than +0.0001 or less than -0.0001 , respectively. |SURPRISE| is the absolute value of earnings surprise for the quarter, defined as actual earnings minus the prevailing median analyst estimate, deflated by stock price three trading days prior to the report date of quarterly earnings. LOSS is an indicator variable set to 1 if actual earnings is negative. DISPERSION is the standard deviation of prevailing analyst estimates for the current period's earnings. PRIOR_RET is the 90-day return ending three days prior to the earnings release date. $\log (\mathrm{MVE})$ is the $\log$ of the market value of the firm's equity (price multiplied by shares outstanding) measured three days before the report date of quarterly earnings. $\log ($ NUMEST) is the $\log$ of the number of analyst earnings forecasts for that quarter that are not more than 90 days old. PROPMB is the proportion of the previous four quarters that the firm's reported earnings met or exceeded analysts' prevailing median consensus estimates. VOLATILITY is the standard deviation of daily stock returns over the 90 -day period ending three days prior to earnings release. ROA net income divided by beginning total assets 
dismissed versus nondismissed indicator to identify variation in the treatment effect of litigation, suggesting that lawsuits that survive dismissal (i.e., those that are settled) are the more severe lawsuits that take longer to resolve, because of the strength of the case. Thus increased disclosure may not cause the worse outcome; rather, it may merely pick up cases where the incentives to disclose were higher because of the severity of the negative news and, consequently, the case was stronger. ${ }^{18}$ Nonetheless, consistent with Rogers and Van Buskirk (2009), the evidence of Cutler et al. (2019) suggests that litigation may cause managers to view disclosure as costly. In our upcoming tests, we examine whether litigation revises managers' beliefs about the costs of disclosure and whether this varies based on the sign, timing, and venue of disclosure as well as managers' experience during litigation.

\subsection{Do managers adopt a more conservative disclosure strategy in response to litigation?}

The evidence in Panel A of Table 5 indicates that managers reduce their overall level of disclosure following lawsuit filings. Panel B of Table 5 examines the sign of disclosure. Columns [1] and [2] focus on the frequency of positive and negative guidance (POSITIVE_GUIDANCE_COUNT and NEGATIVE_GUIDANCE_COUNT), respectively. If litigation causes managers to revise their beliefs about the costs and benefits of their current level of disclosure (regardless of the sign of the news), we expect to observe a negative coefficient on SUED $\times$ POST-SUIT in both columns [1] and [2]. If, however, litigation reinforces the value of cautionary warnings (along with the costs of ex post inaccurate positive guidance), then we expect to observe a negative coefficient on the interaction of SUED $\times$ POST-SUIT in column [1] and a positive coefficient on $S U E D \times P O S T-S U I T$ in column [2]. That is, if litigation causes managers to reassess the costs and benefits associated with the particular sign of their disclosures (and not just overall quantity), we expect managers to reduce the number of good news forecasts while increasing the incidence of bad news forecasts.

We find evidence consistent with the latter explanation. Specifically, in columns [1] and [2] we observe a negative and positive coefficient on SUED $\times$ POST-SUIT for positive and negative guidance, respectively. Thus, consistent with Skinner (1994), the lawsuit filing appears to have reinforced the contrasting costs and benefits of positive versus negative forecasts. The asymmetric response also aligns with evidence of Nelson and Pritchard (2007), who find that managers increase their use of cautionary language in response to increases in litigation risk but do not remove cautionary language when litigation risk declines.

The evidence in columns [1] and [2] confirms that managers view the costs and benefits of positive versus negative guidance differently when deciding whether to continue to provide guidance after the lawsuit. Because most lawsuits allege that managers' warnings were insufficient during the class period (Table 1, Panel C), this leads one to question whether managers also adjust the timing of their

\footnotetext{
18 That is, the link between increased disclosure and worse outcomes (where nondismissals are used as a proxy for worse outcomes as opposed to a measure of the severity of the lawsuit) is subject to the classic endogeneity observed empirically by Field et al. (2005) and theoretically by Marinovic and Varas (2016): the incentives to increase disclosure as well as the likelihood of litigation (along with the likelihood that the case survives dismissal) increase with the severity of the negative news.
} 
forecasts. Thus, in columns [3] and [4], we examine the timeliness of the forecasts (GUIDANCE_HORIZON). If litigation reinforces the value of early, cautionary warnings (as well as underscores the costs of ex post inaccurate positive guidance), we expect to observe a negative coefficient on the interaction of $S U E D \times$ POST-SUIT when examining the timeliness of positive forecasts (column [3]) and a positive coefficient on $S U E D \times P O S T$-SUIT when examining the timeliness of negative forecasts (column [4]). As evidenced by the contrasting coefficients on the interaction term, we find that good news arrives later while bad news arrives earlier in the quarter for lawsuit firms in the post-lawsuit period (as compared to the changes in forecast horizon observed for the nonlawsuit firms). ${ }^{19}$

Because the tabulated regressions in Panel B of Table 5 count only positive or negative guidance activity in the dependent variable, we also consider the extent to which this is effectively also cutting on the main dependent variable in Panel A (i.e., the level of guidance in general). In untabulated analyses, we have explored various regression specifications, and all results remain robust. In particular, the results presented in Panel B of Table 5 are robust to measuring our dependent variable as the proportion of the total guidance given during the quarter that was negative (e.g., GUIDANCE_COUNT_ALL using negative guidance scaled by the sum of positive and negative GUIDANCE_COUNT_ALL). In measuring the proportion of negative guidance, we use a number of different approaches that either include or exclude firm-quarters with no guidance as well as whether the denominator in the proportion includes confirming (i.e., neither positive nor negative) guidance. In addition, the results are also robust to estimating our main regression specifications using a negative binomial distribution.

In summary, the evidence in Table 5 corroborates the main finding of Rogers and Van Buskirk (2009): the total quantity of guidance falls following litigation. Yet it suggests a different conclusion in terms of whether litigation causes managers to doubt the value of all disclosures - especially cautionary guidance. Rogers and Van Buskirk (2009) infer from the absence of significant increases in signed management forecast error, earnings surprise, or earnings announcement abnormal returns that managers do not change the sign of their forecasts to adopt a more conservative disclosure strategy. In contrast, our tests that directly consider the sign of the forecast indicate that litigation does, in fact, intensify managers' efforts to avoid negative earnings surprises: while managers reduce and delay their forecasts of positive (and confirming) earnings news (which drives the reduction in overall disclosure level), bad news warnings actually increase and become timelier. ${ }^{20}$ Nonetheless, the effect of litigation on managers' disclosure strategies may also depend upon managers' disclosure history and their experience in litigation.

\footnotetext{
$\overline{{ }^{19} \text { Because the dependent variable }}$ is the mean horizon of guidance given during the quarter, we limit our analyses to firm-quarters where the firm actually gave guidance. If we set GUIDANCE HORIZON $=0$ for firm quarters in which no guidance was given, our result in column [3] remains unchanged, while the interaction coefficient in column [4] remains positive but the significance falls slightly below $10 \%$. For tests that examine guidance frequency, we do not restrict the sample to firm-quarters in which managers provided guidance; i.e., GUIDANCE_COUNT = 0 for some firm-quarters.

${ }^{20}$ Positive and negative guidance are mutually exclusive subsets, but there is also an (untabulated) subset of confirming guidance (i.e., neutral forecasts). Thus both positive and confirming guidance decrease in frequency and become less timely, while negative guidance increases and becomes timelier in the postlawsuit period. This explains the overall reduction in guidance and the decline in timeliness. All of our results remain if we include the confirming guidance with the positive subset.
} 


\subsection{Does the response differ depending on the experience during litigation?}

Next, we conduct cross-sectional tests to strengthen our attribution of litigation as a disciplining mechanism. Rogers and Van Buskirk (2009) conclude that scrutiny causes lawsuit managers to reduce disclosure, because they emerge from litigation with the belief that even their good faith disclosures will get them into trouble. To focus on a subset of managers for which this premise should be especially pronounced, we partition the sample based on the firms' guidance history. Specifically, we code an indicator variable $(G U I D E R=1)$ for firms that provided guidance in the two years prior to the lawsuit filing. For this subsample of guiders $(N=483)$, we expect managers to be especially susceptible to the notion that litigation caused them to believe that their disclosures weren't helpful and, in fact, got them into trouble.

In contrast, for the remaining 171 nonguiding firms, it is more difficult to make a clear prediction. These nonguiders did not directly observe their own disclosures being used against them during litigation, which suggests that they may be less likely to believe that disclosure will get them into trouble. Instead, litigation may cause these managers to begin viewing guidance as valuable and necessary. Yet, because these firms had no history of guidance prior to the lawsuit, this means that litigation would need to push these firms to take on a new commitment to providing guidance - not just an adjustment within their existing policy. Research suggests that the marginal cost of initiating a commitment to guidance may exceed the anticipated benefit (Balakrishnan et al. 2014; Clinch and Verrecchia 2015). Thus this shifts the focus from the intensive margin (i.e., guidance frequency) to the extensive margin (i.e., likelihood of becoming a guider) for this nonguiding subsample.

To explore these cross-sectional differences, Panel A of Table 6 repeats our main tests after sorting the sample firms into these two groups. As shown in the first three columns, our findings suggest that GUIDERS do not adopt the belief that a higher level of disclosure harmed their cases or that even their good faith disclosures will be used against them. Rather, we find that those managers whose own guidance faced scrutiny for being insufficient continue to view disclosure as a valuable tool to bridge expectations gaps: managers who gave "insufficient" prior warnings give cautionary guidance earlier and more frequently in the post-lawsuit period.

Shifting focus to the nonguiders, we do not detect significant changes in their guidance frequency (see specifications [4] through [6]). Nonetheless, we do find that these firms are more likely to begin guiding in response to litigation. In particular, as shown in specifications [7] and [8]), when comparing the lawsuit firms without a history of guidance to the nonsued (control) firms that also were nonguiders in the preperiod, we find that the lawsuit firms are more likely to begin providing guidance in the quarter and year following the lawsuit filing.

As an alternative approach to examining variation in managers' experience during the litigation process, we identify those managers whose lawsuits exposed them to heightened media scrutiny. In particular, in Panel B of Table 6, we partition the lawsuit sample based on at-or-above-median changes in the level of media coverage surrounding their litigation matters (VISIBILITY = 1). We use the Key Developments database from Capital IQ to identify material news events pertaining to litigation occurring in the days surrounding the lawsuit filing (i.e., LIT_NEWS_ITEMS). We count the number of litigation-related news items (i.e., Capital IQ Key Development Item \#25) during days 


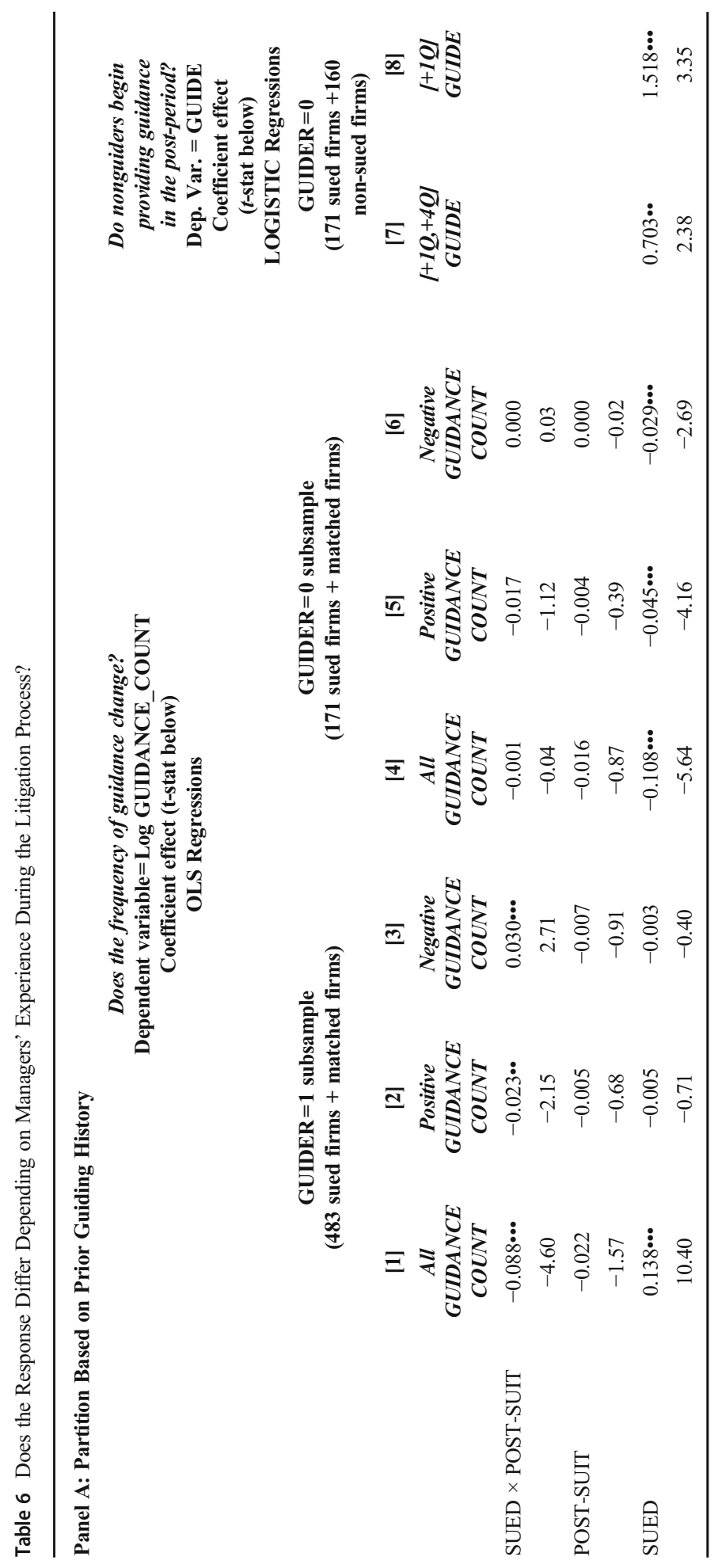




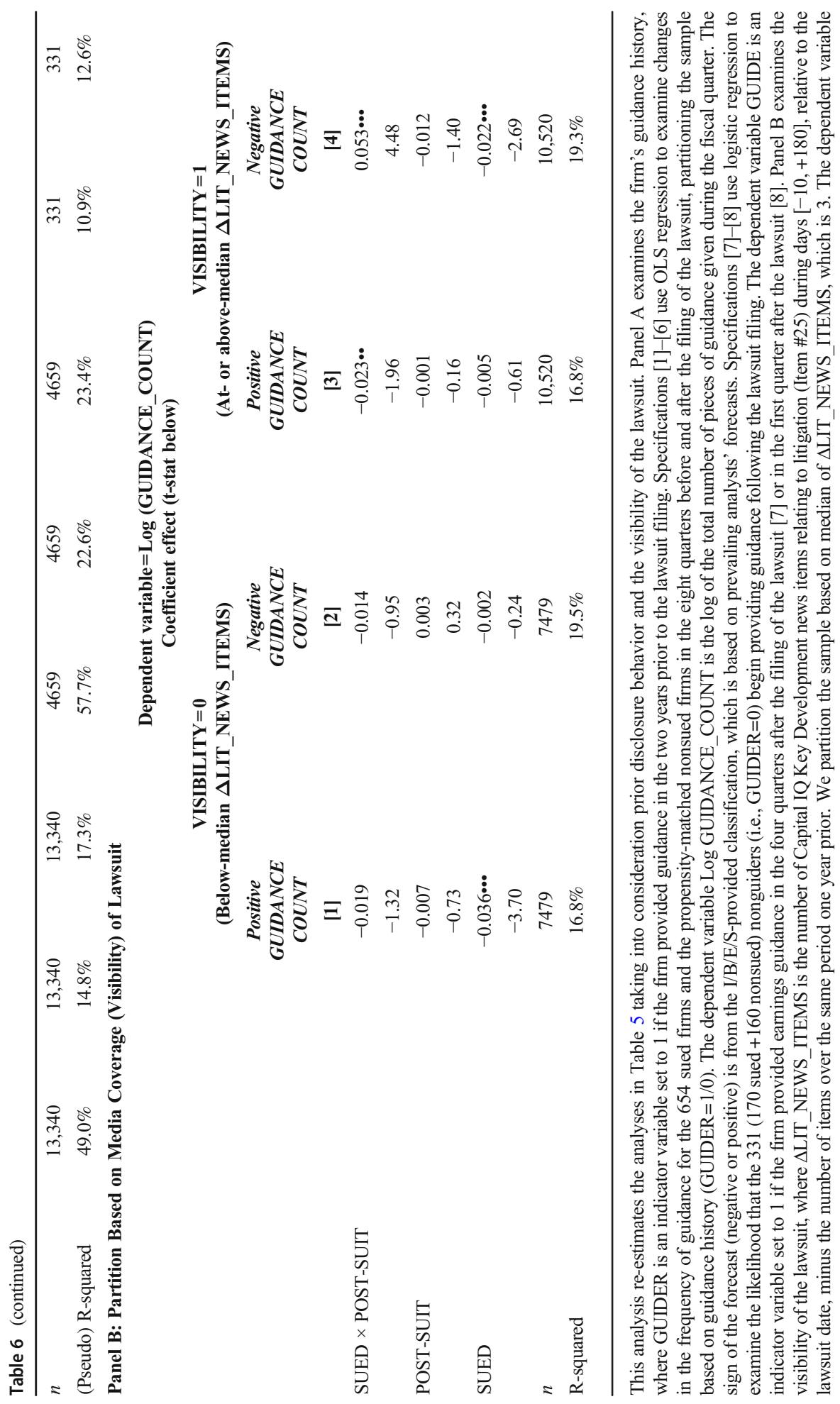




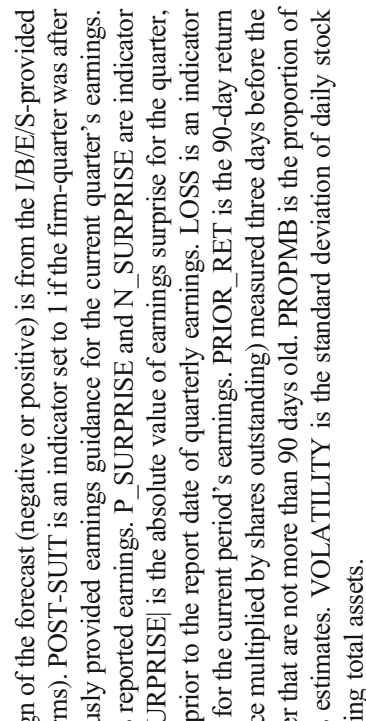

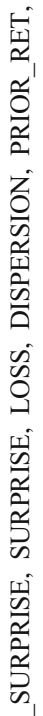

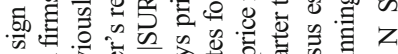

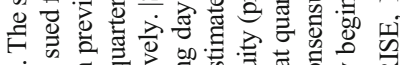

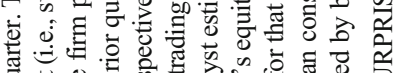

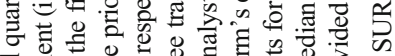

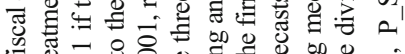

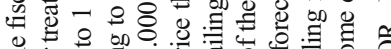

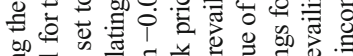

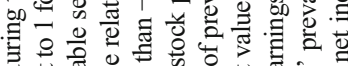

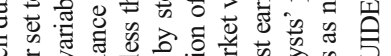

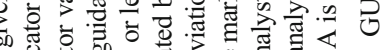

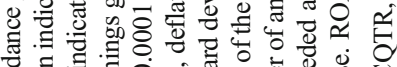

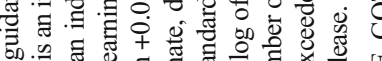

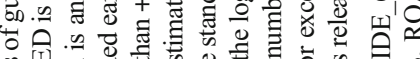

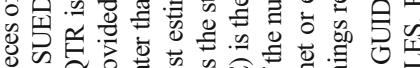

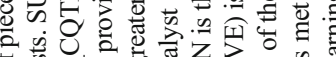

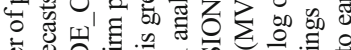

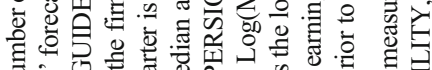

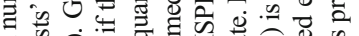

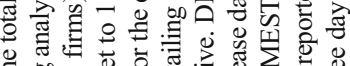

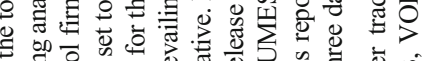

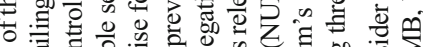
on 000 .

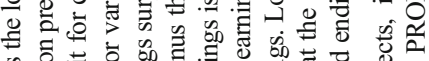

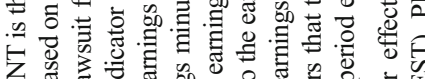

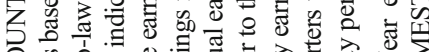

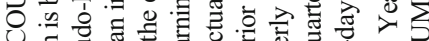

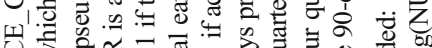

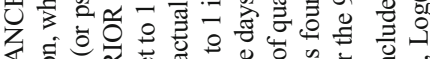

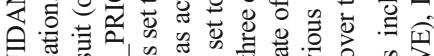

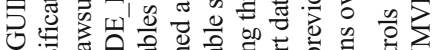

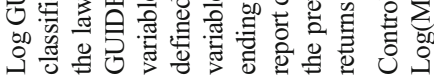


$[-10,+180]$, relative to the lawsuit filing date. To calculate an abnormal measure of litigation-related press coverage ( $\left.\triangle L I T \_N E W S \_I T E M S\right)$, we difference this number from the number of litigation-related news items that occurred in the same period in the prior year. We then partition the sample based on the median $\triangle L I T \_N E W S \_I T E M S$ of three for the full sample and re-estimate our main regressions from Table 5 .

We expect these high visibility managers to be especially susceptible to the notion that litigation caused them to believe that their disclosures aren't helpful and, in fact, may get them into trouble. Comparing the first two columns to the last two columns in Panel B of Table 6, we observe that our earlier findings of more frequent and timely warnings following litigation concentrate among those lawsuit firms that experienced above-median changes in the level of media coverage surrounding their litigation matters.

Partitioning the sample based on litigation-related press coverage might also partition the sample based upon the severity of the litigation. To investigate this possibility, we examine the extent to which firm and lawsuit characteristics differ across this partition. When examining median differences, we do not detect significant differences in any of the following firm or lawsuit characteristics: size of the firm (in terms of $M V E$ or ASSETS), length of the litigation class period, return performance during the litigation class period, days until lawsuit resolution, incidence of settlement, or settlement amount. Consequently, it does not appear that partitioning the sample based on increased incidence of litigation-related media coverage also partitions the sample based on the severity of the lawsuit.

In summary, narrowing in on lawsuit managers who experienced increased legal and media scrutiny during litigation, our evidence suggests that such scrutiny underscored the value of timely cautionary disclosure to these managers. At the same time, we find no evidence to suggest that any subsample of managers responded to litigation by reducing their cautionary guidance. Combined, this evidence contradicts the conclusion that scrutiny during litigation prompts managers to begin viewing all disclosureespecially good faith, cautionary disclosures - as more costly.

\subsection{Do managers adjust the content of their disclosures in other venues following litigation?}

Next, we broaden our analysis to other disclosure venues. The univariate statistics presented in Table 3 indicate that lawsuit managers do not reduce disclosures they make via press releases. Instead, they increase them. In Table 7, we test this hypothesis by re-estimating Eq. (1) using the count of firm-initiated press releases issued during the quarter as the dependent variable. Given the change in focus to press releases from guidance, we control for the prior level of firm-initiated press releases with the inclusion of lagged PR_COUNT in these regressions. ${ }^{21}$ Panel A of Table 7 depicts the distribution of press release categories in our sample. Note that $26 \%$ of press releases relate to earnings-related disclosures, $19.2 \%$ to product and services, and $10.9 \%$ to marketing.

Panel B of Table 7 shows multivariate results when using press releases as the dependent variable. In contrast to the overall reduction in guidance documented in

\footnotetext{
${ }^{21}$ We limit our analyses to those firms that we could identify as being covered by RavenPack.
} 
Table 7 Do Managers Adjust the Content of Their Disclosures in Other Venues Following Litigation?

Panel A: Distribution of RavenPack press release categories

$\begin{array}{lc}\text { Category } & \text { Percentage } \\ \text { Earnings } & 26.0 \% \\ \text { Products and services } & 19.2 \% \\ \text { Marketing } & 10.9 \% \\ \text { Labor issues } & 8.4 \% \\ \text { Investor relations } & 6.4 \% \\ \text { Partnerships } & 5.4 \% \\ \text { Dividends } & 4.5 \% \\ \text { Acquisitions and mergers } & 3.9 \% \\ \text { Credit ratings } & 3.7 \% \\ \text { Revenues } & 3.1 \% \\ \text { Equity actions } & 2.4 \% \\ \text { Legal } & 2.2 \% \\ \text { All others }(<2 \% \text { each) } & 4.0 \% \\ \text { Total } & 100 \%\end{array}$

Panel B: Frequency of firm-initiated press releases before and after lawsuit filings

\begin{tabular}{|c|c|c|c|}
\hline & Co & $\begin{array}{l}\text { nt variable = } \\
\text { fCOUNT) } \\
\text { fect (t-stat belo }\end{array}$ & \\
\hline & $\begin{array}{c}A l l \\
\text { PR_COUNT }\end{array}$ & $\begin{array}{c}\text { Positive } \\
\text { PR_COUNT }\end{array}$ & $\begin{array}{c}\text { Negative } \\
\text { PR_COUNT }\end{array}$ \\
\hline & [1] & [2] & [3] \\
\hline SUED $\times$ POST-SUIT & $0.044 \bullet$ & -0.003 & $0.100 \bullet \bullet \bullet$ \\
\hline & 1.78 & -0.08 & 3.67 \\
\hline POST-SUIT & $0.032 \bullet$ & 0.031 & -0.029 \\
\hline & 1.84 & 1.29 & -1.51 \\
\hline SUED & $0.031 \bullet$ & $0.100 \bullet \bullet$ & $0.080 \bullet \bullet \bullet$ \\
\hline & 1.82 & 4.33 & 4.25 \\
\hline$n$ & 11,992 & 11,992 & 11,992 \\
\hline R-squared & $42.0 \%$ & $34.2 \%$ & $13.9 \%$ \\
\hline
\end{tabular}


Table 7 (continued)

Panel C: Conference call disclosure before and after lawsuit filings

Dependent variable $=$ CC_DISCLOSURE

Coefficient effect (t-stat below)

\begin{tabular}{|c|c|c|c|c|c|c|c|}
\hline & $\begin{array}{c}\text { Log total } \\
\text { words } \\
{[1]}\end{array}$ & $\begin{array}{c}\text { Log mono } \\
\text { words } \\
{[2]}\end{array}$ & Mono \% & \# Qs & $\begin{array}{c}\text { Log \# } \\
\text { analysts } \\
{[5]}\end{array}$ & $\begin{array}{c}\text { Q per } \\
\text { analyst } \\
{[6]}\end{array}$ & $\begin{array}{c}\text { Response } \\
\text { per Q } \\
{[7]}\end{array}$ \\
\hline \multirow{2}{*}{$\begin{array}{l}\text { SUED } \times \text { POST }- \\
\text { SUED }\end{array}$} & 0.022 & $0.067 \bullet \bullet$ & $0.037 \bullet . \bullet$ & $-1.769 \bullet . \bullet$ & $-0.056 \bullet$ & 0.045 & 11.23 \\
\hline & 0.75 & 2.09 & 4.09 & -3.05 & -1.75 & 0.13 & 0.91 \\
\hline \multirow[t]{2}{*}{ POST-SUED } & $-0.056 \bullet \bullet$ & -0.028 & $0.011 \bullet$ & $-1.328 \bullet \bullet \bullet$ & $-0.063 \bullet \bullet$ & $-0.692 \bullet \bullet$ & 7.666 \\
\hline & -2.76 & -1.26 & 1.83 & -3.37 & -2.90 & -3.07 & 0.93 \\
\hline \multirow[t]{2}{*}{ SUED } & $0.057 \bullet \bullet$ & $0.079 \bullet . \bullet$ & 0.008 & $-1.496 \bullet \bullet \bullet$ & -0.028 & -0.083 & $22.30 \bullet$ \\
\hline & 2.68 & 3.43 & 1.26 & -3.63 & -1.24 & -0.35 & 2.56 \\
\hline \multirow[t]{2}{*}{ GUIDE_CQTR } & -0.007 & $0.054 \bullet \bullet \bullet$ & $0.027 \bullet \bullet$ & $-2.021 \bullet \bullet$ & -0.019 & $-0.358 \bullet$ & $23.68 \bullet \bullet$ \\
\hline & -0.40 & 2.84 & 5.12 & -5.90 & -1.04 & -1.81 & 3.25 \\
\hline \multirow[t]{2}{*}{ GUIDE_PRIOR } & $0.058 \bullet \bullet$ & 0.023 & $-0.019 \bullet \bullet$ & $2.734 \bullet \bullet$ & $0.153 \bullet \bullet$ & $0.392 \bullet \bullet$ & -5.200 \\
\hline & 3.45 & 1.25 & -3.72 & 8.33 & 8.46 & 2.07 & -0.75 \\
\hline \multirow[t]{2}{*}{ P_SURPRISE } & $-0.048 \bullet$ & $-0.053 \bullet$ & -0.005 & 0.582 & 0.012 & 0.445 & -2.022 \\
\hline & -1.80 & -1.83 & -0.62 & 1.12 & 0.43 & 1.46 & -0.18 \\
\hline \multirow[t]{2}{*}{ N_SURPRISE } & -0.010 & -0.032 & $-0.015 \bullet$ & $1.360 \bullet \bullet$ & 0.011 & $0.653 \bullet \bullet$ & -9.113 \\
\hline & -0.34 & -1.01 & -1.77 & 2.42 & 0.35 & 1.99 & -0.75 \\
\hline \multirow[t]{2}{*}{ |SURPRISE| } & 0.015 & $0.403 \bullet \bullet$ & $0.206 \bullet \bullet \bullet$ & $-6.335 \bullet \bullet$ & -0.083 & $-3.384 \bullet \bullet$ & -24.43 \\
\hline & 0.10 & 2.40 & 4.41 & -2.10 & -0.47 & -1.97 & -0.38 \\
\hline \multirow[t]{2}{*}{ LOSS } & 0.024 & $0.044 \bullet$ & 0.008 & $-1.286 \bullet \bullet \bullet$ & 0.013 & $-0.470 \bullet$ & 13.43 \\
\hline & 1.05 & 1.81 & 1.22 & -2.92 & 0.53 & -1.85 & 1.47 \\
\hline \multirow[t]{2}{*}{ DISPERSION } & -0.020 & -0.058 & -0.017 & $4.138 \bullet \bullet \bullet$ & $-0.238 \bullet \bullet$ & $1.825 \bullet \bullet$ & $-48.57 \bullet$ \\
\hline & -0.26 & -0.70 & -0.73 & 2.79 & -2.72 & 2.26 & -1.67 \\
\hline \multirow[t]{2}{*}{ PRIOR_RET } & $-0.099 \bullet \bullet$ & $-0.116 \bullet \bullet$ & -0.011 & -0.175 & 0.044 & 0.127 & $-22.53 \bullet$ \\
\hline & -3.31 & -3.55 & -1.19 & -0.30 & 1.34 & 0.39 & -1.88 \\
\hline \multirow[t]{2}{*}{ Log(MVE) } & $0.063 \bullet \bullet$ & $0.063 \bullet \bullet \bullet$ & 0.002 & -0.040 & $0.071 \bullet \bullet$ & $-0.563 \bullet \bullet$ & $16.72 \bullet \bullet$ \\
\hline & 10.58 & 9.72 & 1.18 & -0.34 & 11.05 & -8.44 & 6.79 \\
\hline \multirow[t]{2}{*}{ Log(NUMEST) } & $0.083 \bullet \bullet$ & $0.023 \bullet$ & $-0.027 \bullet \bullet$ & $2.136 \bullet \bullet \bullet$ & $0.230 \bullet \bullet$ & -0.011 & $13.55 \bullet \bullet$ \\
\hline & 6.95 & 1.76 & -7.43 & 9.09 & 17.77 & -0.08 & 2.74 \\
\hline \multirow[t]{2}{*}{ PROPMB } & -0.023 & -0.047 & -0.009 & $-0.950 \bullet$ & $-0.074 \bullet \bullet$ & 0.373 & -13.72 \\
\hline & -0.88 & -1.61 & -1.08 & -1.83 & -2.58 & 1.27 & -1.27 \\
\hline \multirow[t]{2}{*}{ VOLATILITY } & $1.008 \bullet \bullet$ & -0.144 & $-0.748 \bullet$ & $90.50 \bullet \bullet$ & $4.979 \bullet \bullet$ & $-8.360 \bullet$ & -149.8 \\
\hline & 2.31 & -0.30 & -5.66 & 10.63 & 10.04 & -1.77 & -0.85 \\
\hline \multirow[t]{2}{*}{ ROA } & -0.005 & $-0.475 \bullet \bullet$ & $-0.192 \bullet \bullet$ & $13.43 \bullet \bullet \bullet$ & $0.670 \bullet \bullet$ & $5.705 \bullet \bullet$ & -34.60 \\
\hline & -0.03 & -2.89 & -4.21 & 4.57 & 4.06 & 3.12 & -0.59 \\
\hline$n$ & 11,679 & 11,679 & 11,679 & 11,679 & 11,679 & 11,679 & 11,679 \\
\hline R-squared & $3.8 \%$ & $3.7 \%$ & $9.3 \%$ & $5.7 \%$ & $17.7 \%$ & $2.1 \%$ & $2.4 \%$ \\
\hline
\end{tabular}

These analyses focus on disclosure behavior via press releases and conference calls before and after litigation. We obtain press release information from RavenPack and limit analysis to sample and control firms with RavenPack coverage eight quarters before and after the filing of the lawsuit. Panel A displays the topical distribution of all press releases in the RavenPack database for the firms in our sample. Panel B analyzes changes in press release activity. Log PR_COUNT is the log of one plus the total number of press releases 
about the firm in the quarter appearing in the RavenPack database, among items with a relevance score of 100. Press releases with an event sentiment score of less (greater) than 50 are classified as negative (positive). Panel $\mathrm{C}$ analyzes quarterly earnings conference call characteristics. Log Total Words is the $\log$ of 1 plus the total number of words spoken by all parties in the conference call. Mono Words is the log of 1 plus the total number of words spoken in the opening monologue session of the conference call. Mono \% is the number of words in the opening monologue as a proportion of the total words spoken by all parties in the entirety of the conference call. \# Qs is the total number of analyst questions fielded by managers during the conference call. Log \# analysts is the $\log$ of 1 plus the number of analysts participating on the conference call. Q per analyst is the number of questions asked during the call scaled by the number of analysts participating on the call. Response per $\mathrm{Q}$ is the average number of words spoken in response to each question fielded.

Controls included: Year effects, insider trading measures, Lag PR_COUNT, P_SURPRISE, N_SURPRISE, SURPRISE, LOSS, DISPERSION, PRIOR_RET, Log(MVE), Log(NUMEST), PROPMB, VÖLATILITY, SALES, ROA.

Table 5, column [1] of Panel B suggests that the overall number of firm-initiated press releases actually increases in the post-period for the lawsuit firms, as compared to the matched firms. Yet, consistent with our earlier guidance findings in Table 5, the remaining columns suggest this increase is driven by an increase in those firminitiated press releases that discuss negative news, as evidenced by the large and significant coefficient for SUED $\times$ POST-SUIT in column [3].

Shifting attention to firms' quarterly earnings conference calls, Panel $\mathrm{C}$ examines changes in conference call dynamics surrounding the lawsuit filing. ${ }^{22}$ In particular, in Panel $\mathrm{C}$ of Table 7, we examine changes in disclosure in the opening script as well as changes in the extent to which managers field questions. As shown in columns [2] and [3], our results suggest that managers lengthen their introductory remarks (both in proportion to the total words spoken and in the absolute number of words) in the postlawsuit period. At the same time, the evidence presented in column [1] suggests that the overall length of the earnings call (measured as the number of words spoken by all parties on the call) does not significantly change. Thus the relative proportion of the call devoted to the Q\&A portion seems to decrease. Despite this, however, we find no evidence that managers decrease their responsiveness to questions after being sued. Although the number of questions fielded by management does fall after the call (column [4]), so does the number of analysts participating (column [5]), so that the number of questions per call scaled by analysts participating does not significantly change (column [6]). Moreover, the average length of each response per analyst question does not change (column [7]). Similarly, in untabulated analyses, we detect no change in "non-answer" rates, as measured following Gow et al. (2019). ${ }^{23}$

In summary, expanding our analyses to consider additional channels of disclosure beyond those explored by Rogers and Van Buskirk (2009), we find no evidence of reduced overall disclosure. Instead, we find that firms' press releases that discuss negative news increase in the post-lawsuit period, while their press releases discussing

\footnotetext{
${ }^{22}$ Rogers and Van Buskirk (2009) find that managers are less likely to host an earnings-related conference call following litigation. Because our sample period begins after Reg FD, virtually all of our sample firms hold quarterly earnings conference calls. As such, our analyses focus on changes in the content of conference calls - as opposed to whether the call occurs.

${ }^{23}$ Specifically, Gow et al. (2019) use linguistic analysis to develop an approach to measuring "non-answers" to analysts' questions during conference calls. In doing so, they categorize answers as "refuse," "unable" or "after-the-call" based on the nature of the "non-answer" given by managers in the call. Using their approach to measurement, we detect no change in any category of non-answer for our lawsuit firms.
} 
positive and neutral news remain unchanged. We also find that managers do not limit the information they provide via their conference calls. After a lawsuit, managers increase the length of their introductory remarks while sustaining their prior level of responsiveness to analyst questions. Overall, this evidence suggests that many managers respond to litigation by not only emphasizing early, cautionary warnings but also maintaining (or even increasing) disclosure in other venues. Building upon this evidence, our next analysis examines more general changes in firms' information environment surrounding litigation.

\subsection{Does the overall information environment of the firm change following litigation?}

Our findings thus far indicate that guiding firms increase the frequency and timeliness of their bad news guidance while maintaining or increasing disclosure via alternative channels. In Table 8, we investigate changes in indirect measures of information flow following litigation. In the first two specifications, we examine changes in the accuracy of managers' forecasts; in the next four columns, we focus on analysts' forecasts; in the final specification, we examine liquidity.

As shown in columns [1] and [2], consistent with Rogers and Van Buskirk (2009), we detect no changes in unsigned or signed management forecast error. That is, conditional upon the decision to issue a forecast, we find no evidence to suggest that managers' willingness or ability to provide an accurate forecast changes in the postlawsuit period. ${ }^{24}$ Looking at analyst forecast error, however, we do detect certain changes in earnings surprises. Specifically, as shown in column [3], we find that absolute earnings surprises increase. Additionally, while signed earnings surprises do not significantly increase (column [4]), the likelihood of positive earnings surprise (i.e., our P_SURPRISE and BEAT variables on columns [5] and [6] logistic regressions) increases. This suggests that the increased frequency of negative news forecasts (and accompanying increases in disclosure via press releases and conference calls) may help walk down expectations in the post-lawsuit period. Additionally, we find no evidence that stock liquidity (as measured using the Amihud stock illiquidity measure) changes. $^{25}$ Thus, lawsuit managers - including those managers who did not take advantage of warning in the past - appear to respond to litigation with a renewed emphasis on cautionary guidance, and, in so doing, they decrease the likelihood that the firm reports another potentially lawsuit-triggering negative earnings surprise.

\section{Conclusion}

Research calls into question litigation's effectiveness as a corporate governance mechanism - finding that litigation causes managers to reduce disclosure, perhaps stemming from a belief that even their good faith disclosures will be used against

\footnotetext{
${ }^{24}$ Of course, we can measure management forecast error only for those firm-quarters in which management chose to provide guidance. In untabulated analyses, we use the change in earnings over the same quarter in the prior year for firm-quarters in which management did not provide guidance, and we find similar results.

${ }^{25}$ We also use bid-ask spread and a modified Amihud illiquidity measure as suggested in Barardehi et al. (2020), and find no changes in liquidity using these alternative measures as well.
} 


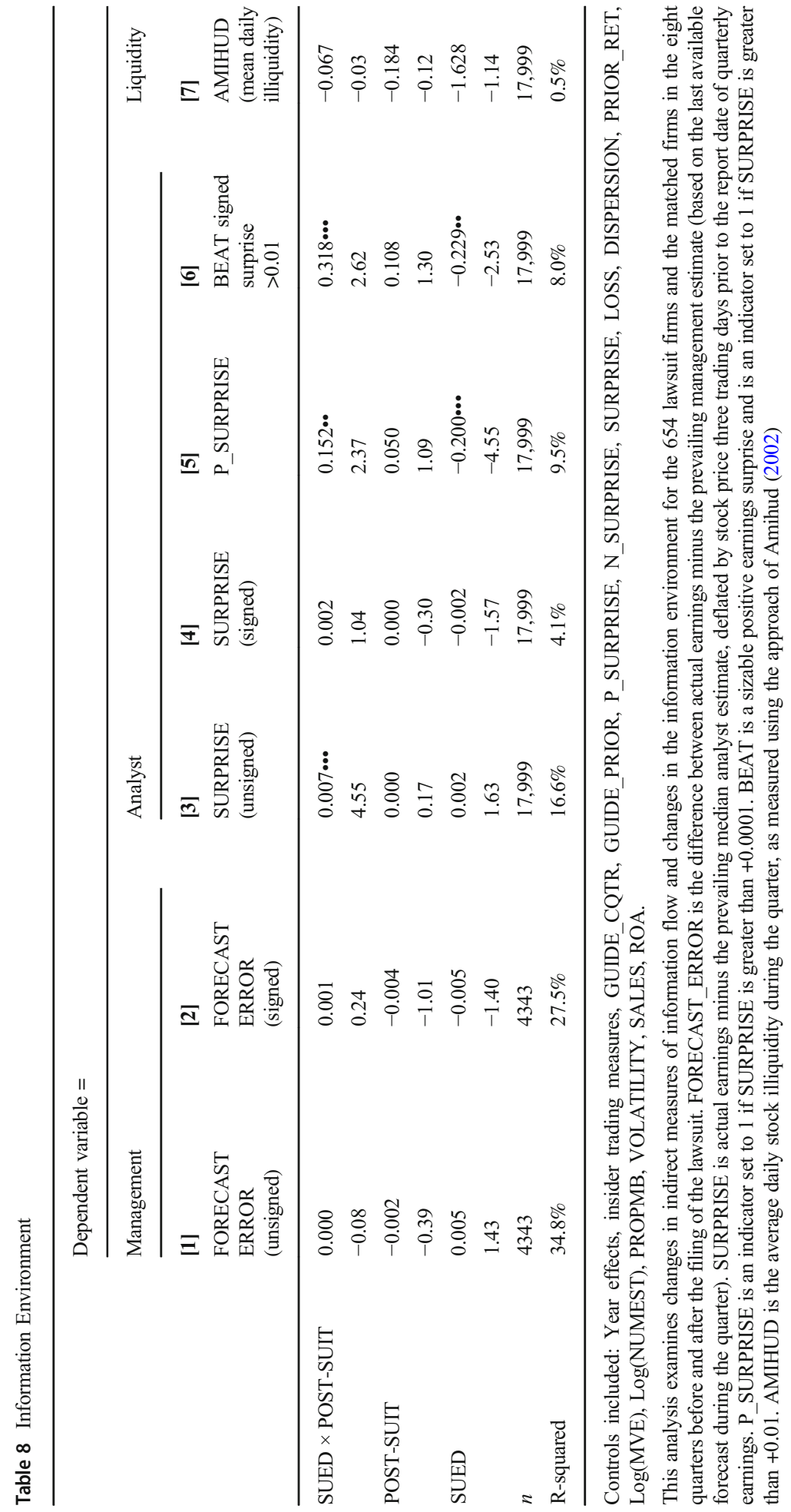


them. From shareholders' perspective, this finding is concerning, given the documented litigation and other information environment benefits associated with disclosure (Field et al. 2005; Anantharaman and Zhang 2011; Billings and Cedergren 2015). This finding is also concerning from the standpoint of regulators, as it calls into question the extent to which litigation disciplines managers. Further, proponents of litigation reform are often concerned that abusive litigation constrains managers' willingness to openly communicate forward-looking information to the marketplace (Johnson et al. 2000; Johnson et al. 2001; Johnson et al. 2007).

We consider unexplored dimensions of disclosure and alternative channels of disclosure to provide additional evidence that speaks to the role that litigation plays in shaping managers' disclosure strategies. Consistent with Skinner (1994)'s classic legal liability hypothesis, we find that, while managers reduce and delay forecasts of positive earnings news following litigation, they increase the frequency and timeliness of their bad news forecasts. We also find that managers maintain (if not increase) the information they provide via press releases and during conference calls following litigation. Supporting the notion that managers use disclosure to walk down expectations, additional analyses document an increase in the likelihood that lawsuit firms report earnings that beat consensus forecasts in the post-lawsuit period.

Collectively, our evidence suggests that following litigation managers continue to view disclosure as a valuable tool that shapes their firms' information environments and reduces expected legal costs. Thus our evidence reconciles the finding that managers respond to litigation by reducing disclosure with the growing body of literature that finds that managers seek to and do use disclosure to lower their firms' litigation risk. At the same time, our evidence supports an important alternative viewpoint of how firms respond to litigation as well as the effectiveness of litigation as a disciplining mechanism.

\section{Appendix}

Variable definitions

\footnotetext{
ASSETS

$B E A T$

BUNDLED

CC_DISCLOSURE

CEO TURN

CEOCFO

SALES_A $\overline{L L}$

The firm's total reported assets at the beginning of the quarter.

An indicator variable set to 1 if SURPRISE $>+0.01$.

An indicator variable set to 1 if the firm provided guidance during the five-day window surrounding the report date of quarterly earnings.

The total number of words spoken by all parties in the earnings call (Total words), the total words spoken in the opening monologue (Mono words), Mono words as a percentage of Total words (Mono \%), the total number of analyst questions fielded by managers (\#Qs), the number of analysts participating in the call (\# analysts), the number of analysts questions scaled by the number of analysts $(Q$ per analyst), and the average number of words spoken in response to each question fielded (Response per $Q$ ). We obtain conference call transcripts from Thomson One StreetEvents.

An indicator variable set to 1 if the firm appoints a new CEO in the year following the lawsuit filing.

The total dollar value of CEO and CFO insider sales (scaled by beginning quarter market value) during the quarter. We obtain insider trading information from the Thomson Reuters Insider Trading database.
} 
(continued)

\begin{tabular}{cl}
\hline DISPERSION & $\begin{array}{l}\text { The standard deviation of prevailing analyst estimates for the current period's } \\
\text { earnings. }\end{array}$
\end{tabular}

FORECAST_ERROR The difference between actual earnings minus the prevailing management estimate (based on the last available forecast during the quarter).

GUIDANCE_COUNT The total number of pieces of guidance that the firm provided related to a fiscal quarter. For example, a revenue forecast and an earnings forecast provided on the same date are each treated as a piece of guidance. We code positive and negative guidance (POSITIVE GUIDANCE COUNT and

NEGATIVE_GUIDANCE_COUNT) using analysts' prevailing estimates (following $\mathrm{I} / \mathrm{B} / \mathrm{E} / \mathrm{S})$. All results are robust to coding positive and negative guidance following the approach developed by Rogers and Van Buskirk (2013).

GUIDANCE_ The number of unique days on which the firm provided guidance relating to a fiscal COUNT_DAYS quarter. For example, a revenue forecast and an earnings forecast given on separate days are counted as two separate items, but a revenue forecast and earnings forecast given on the same day count as one item.

$\boldsymbol{G U I D E}$ An indicator variable set to 1 if the firm provided earnings guidance during the quarter.

$\boldsymbol{G U I D E} \boldsymbol{C Q T R}$ An indicator variable set to 1 if the firm previously provided earnings guidance for the current quarter's earnings.

GUIDANCE The horizon of the guidance, measured as the ending date of the fiscal quarter to HORIZON $^{-}$which the guidance relates minus the date the guidance was given. To aggregate to a quarterly measure, we take the mean of this measure for all forecasts made during the quarter.

GUIDER An indicator variable set to 1 if the firm provided guidance in the two years prior to the lawsuit filing.

GUIDE_PRIOR An indicator variable set to 1 if the firm provided earnings guidance relating to the prior quarter's reported earnings.

HIGHLIT_FPS Indicator variable set to 1 if the firm operates in a "high-litigation" industry, as defined by Francis et al. (1994) and employed by Kim and Skinner (2012). Specifically, "high-litigation" industries include biotechnology (SIC codes 28332836), computers (3570-3577 and 7370-7374), electronics (3600-3674), and retailing (5200-5961).

LITIGATION_RISK The ex ante probability estimate of the likelihood that the firm will be the subject of 10b-5 litigation in the next quarter, measured as the predicted probability derived from a first-stage logit regression in which the dependent variable is an indicator set equal to 1 if the firm faces a lawsuit in the quarter and the independent variables are firm characteristics (including industry membership, firm size, recent performance, share price volatility, return skewness, share turnover, and insider trading).

Specifically, we follow the litigation risk model supplied in Equation (3) of Kim and Skinner (2012) to develop a predicted value of litigation risk as of the prior quarter, and we augment their main model to include insider trading behavior.

LOSS An indicator variable set to 1 if actual earnings is negative.

$\boldsymbol{M V E} \quad$ The market value of the firm's equity (price multiplied by shares outstanding) measured three days before the report date of quarterly earnings.

N_SURPRISE An indicator variable set to 1 if SURPRISE $<-0.0001$.

NEWS_ITEMS The number of Capital IQ Key Development news items not relating to litigation (i.e., excluding Item \#25) during days $[-10,+180]$, relative to the lawsuit date.

NUMEST Number of analyst earnings forecasts for that quarter that are not more than 90 days old.

P_SURPRISE An indicator variable set to 1 if SURPRISE $>+0.0001$.

POST-SUIT An indicator variable set to 1 if the fiscal quarter occurs after the firm is sued (or, for matched control firms, the pseudo lawsuit quarter). 
(continued)

PR_COUNT The total number of firm-initiated press releases about the firm in the quarter. We obtain the press release data from RavenPack and we limit analysis to news items with a relevance score $=100$, i.e., where the entity was prominent in the news story. We classify the content of the press release as negative, neutral, or positive (NEGATIVE_PR_COUNT, POSITIVE_PR_COUNT, and NEUTRAL_PR_COUNT) based on the event sentiment score (ESS) in RavenPack, which is a granular score between 0 and 100 that represents the news sentiment for a given entity by measuring various proxies sampled from the news. An event with ESS $>50$ represents a positive article, whereas one with $\mathrm{ESS}<50$ represents a negative article. Events with $\mathrm{ESS}=50$ are considered neutral.

PRIOR_RET Cumulative 90-day stock return ending three days prior to report date of quarterly earnings.

PROPMB The proportion of the previous four quarters that the firm's reported earnings met or exceeded analysts' prevailing median consensus estimates.

RETURN The firm's cumulative stock return measured over the respective period.

$\boldsymbol{R O A} \quad$ Return on assets, defined as net income divided by beginning total assets.

SALES_ALL The total dollar value of insider sales during the quarter, scaled by the beginning market value of equity. We obtain insider trading information from the Thomson Reuters Insider Trading database.

SALES_GROWTH The firm's percentage change in sales for the quarter.

SKEWNESS The 90-day skewness of daily stock returns over the period measured.

SUED An indicator variable set to 1 if the firm faced an earnings-disclosure-based lawsuit (set to 0 for matched control firms).

SURPRISE Actual earnings minus the prevailing median analyst estimate, deflated by stock price three trading days prior to the report date of quarterly earnings.

TURNOVER The total volume of shares traded during the 90-day period ending three days prior to the report date of quarterly earnings divided by the shares outstanding during this same time period.

VOLATILITY The standard deviation of daily stock returns over the 90-day period ending three days prior to the report date of quarterly earnings.

VOLUME The total turnover of shares over the period measured, scaled by shares outstanding.

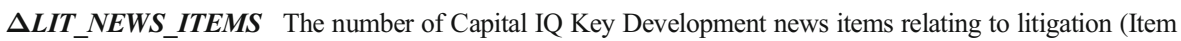
\#25) during days $[-10,+180]$, relative to the lawsuit date, minus the number of items over the same period one year prior. 
Open Access This article is licensed under a Creative Commons Attribution 4.0 International License, which permits use, sharing, adaptation, distribution and reproduction in any medium or format, as long as you give appropriate credit to the original author(s) and the source, provide a link to the Creative Commons licence, and indicate if changes were made. The images or other third party material in this article are included in the article's Creative Commons licence, unless indicated otherwise in a credit line to the material. If material is not included in the article's Creative Commons licence and your intended use is not permitted by statutory regulation or exceeds the permitted use, you will need to obtain permission directly from the copyright holder. To view a copy of this licence, visit http://creativecommons.org/licenses/by/4.0/.

\section{References}

Amihud, Y. 2002. Illiquidity and stock returns: Cross-section and time-series effects. Journal of Financial Markets 5: 31-56.

Anantharaman, D., and Y. Zhang. 2011. Cover me: Managers' responses to changes in analyst coverage in the post-regulation FD period. The Accounting Review 86: 1851-1885.

Baginski, S., J. Hassell, and M. Kimbrough. 2002. The effect of legal environment on voluntary disclosure: Evidence from management earnings forecasts issued in U.S. and Canadian markets. The Accounting Review 77: 25-50.

Balakrishnan, K., M. Billings, B. Kelly, and A. Ljungqvist. 2014. Shaping liquidity: On the causal effects of voluntary disclosure. Journal of Finance 69: 2237-2278.

Barardehi, Y., Bernhardt, D., Ruchti, T. \& Weidenmier, M.. 2020. The night and day of Amihud's liquidity measure. The Review of Asset Pricing Studies, forthcoming. https:/doi.org/10.1093/rapstu/raaa022.

Beyer, A., D. Cohen, T. Lys, and B. Walther. 2010. The financial reporting environment: Review of the recent literature. Journal of Accounting and Economics 50 (2-3): 296-343.

Billings, M.B., and M. Cedergren. 2015. Strategic silence, insider selling and litigation risk. Journal of Accounting and Economics 59: 119-142.

Billings, M.B., R. Jennings, and B. Lev. 2015. On guidance and volatility. Journal of Accounting and Economics 60: 161-180.

Brochet, F., L. Faurel, and S. McVay. 2011. Manager-specific effects on earnings guidance: An analysis of top executive turnovers. Journal of Accounting Research 49: 1123-1162.

Cao, Z., and G. Narayanamoorthy. 2011. The effect of litigation risk on management earnings forecasts. Contemporary Accounting Research 28: 125-173.

Chuk, E., D. Matsumoto, and G. Miller. 2013. Assessing methods of identifying management forecasts: CIG vs. researcher collected. Journal of Accounting and Economics 55: 23-42.

Clinch, G., and R. Verrecchia. 2015. Voluntary disclosure and the cost of capital. Australian Journal of Management 40: 201-223.

Cutler, J., A. Davis, and K. Peterson. 2019. Disclosure and the outcome of securities litigation. Review of Accounting Studies 24: 230-263.

Field, L., M. Lowry, and S. Shu. 2005. Does disclosure deter or trigger litigation? Journal of Accounting and Economics 39: 487-507.

Files, R., E. Swanson, and S. Tse. 2009. Stealth disclosure of accounting restatements. The Accounting Review 84: 1495-1520.

Francis, J., D. Philbrick, and K. Schipper. 1994. Shareholder litigation and corporate disclosures. Journal of Accounting Research 32: 137-164.

Gow, I., Larcker, D., Zakolyukina A.. 2020. Non-answers during conference calls. Working paper. https:// ssrn.com/abstract $=3310360$

Graham, J., C. Harvey, and S. Rajgopal. 2005. The economic implications of corporate financial reporting. Journal of Accounting and Economics 40: 3-73.

Heflin, F., W. Kross, and I. Suk. 2012. The effect of regulation FD on the properties of management earnings forecasts. Journal of Accounting and Public Policy 31: 161-184.

Heflin, F., W. Kross, and I. Suk. 2016. Asymmetric effects of regulation FD on management earnings forecasts. The Accounting Review 91: 119-152.

Houston, J., C. Lin, S. Liu, and L. Wei. 2019. Litigation risk and voluntary disclosure: Evidence from legal changes. The Accounting Review 94: 247-272.

Johnson, M., R. Kasznik, and K. Nelson. 2000. Shareholder wealth effects of the private securities litigation reform act of 1995. Review of Accounting Studies 5: 217-233. 
Johnson, M., R. Kasznik, and K. Nelson. 2001. The impact of securities litigation reform on the disclosure of forward-looking information by high technology firms. Journal of Accounting Research 39: 297-327.

Johnson, M., K. Nelson, and A. Pritchard. 2007. Do the merits matter more? The impact of the private securities litigation reform act. Journal of Law, Economics, and Organization 23: 627-652.

Kim, I., and D. Skinner. 2012. Measuring securities litigation risk. Journal of Accounting and Economics 53: 290-310.

Laux, V., and P. Stocken. 2012. Managerial reporting, overoptimism, and litigation risk. Journal of Accounting and Economics 53: 577-591.

Li, E., C. Wasley, and J. Zimmerman. 2016. The disclose or abstain incentive to issue management guidance. Journal of Law, Finance, and Accounting 1: 187-233.

Lowry, M. 2009. Discussion of "Shareholder litigation and changes in disclosure behavior.". Journal of Accounting and Economics 47: 157-159.

Marinovic, I., and F. Varas. 2016. No news is good news: Voluntary disclosure in the face of litigation. RAND Journal of Economics 47: 822-856.

Naughton, J., T. Rusticus, C. Wang, and I. Yeung. 2019. Private litigation costs and voluntary disclosure: Evidence from the Morrison ruling. The Accounting Review 94: 303-327.

Nelson, K., and Pritchard, A.. 2007. Litigation risk and voluntary disclosure: the use of meaningful cautionary language, 2nd Annual Conference on Empirical Legal Studies Paper, http://papers.ssrn.com/sol3/papers. cfm?abstract id=998590.

Olazábal, A.M. 2000. Safe harbor for forward-looking statements under the private securities litigation reform act of 1995: What's safe and what's not? Dickinson Law Review 105: 1-30.

Ribstein, L. 2006. Fraud on a noisy market. Lewis \& Clark Law Review 10: 153-154.

Rogers, J., and A. Van Buskirk. 2009. Shareholder litigation and changes in disclosure behavior. Journal of Accounting and Economics 47: 136-156.

Rogers, J., and A. Van Buskirk. 2013. Bundled forecasts in empirical accounting research. Journal of Accounting and Economics 55: 43-65.

Rose, A.M. 2008. Reforming securities litigation reform: Restructuring the relationship between public and private enforcement of rule 10b-5. Columbia Law Review 108: 1301-1364.

Sale, H. 2002. Judging heuristics. University of California at Davis Law Review 35: 903-963.

Skinner, D. 1994. Why firms voluntarily disclose bad news. Journal of Accounting Research 32: 38-60.

Skinner, D. 1997. Earnings disclosures and stockholder lawsuits. Journal of Accounting and Economics 23: 249-282.

Publisher's note Springer Nature remains neutral with regard to jurisdictional claims in published maps and institutional affiliations.

\section{Affiliations}

\section{Mary Brooke Billings ${ }^{1} \cdot$ Matthew C. Cedergren $^{2} \cdot$ Svenja Dube $^{3}$}

\section{Mary Brooke Billings}

mary.billings@stern.nyu.edu

Matthew C. Cedergren

mcedergren@scu.edu

Svenja Dube

sdube4@fordham.edu

1 New York University, 44 West Fourth Street, New York 10012 NY, USA

2500 El Camino Real, Santa Clara University, Santa Clara 95053 CA, USA

3 Fordham University, $140 \mathrm{~W}$ 62nd St, New York 10023 NY, USA 